\title{
Pharmacokinetics and Toxicokinetics Roles of Membrane Transporters at Kidney Level
}

\author{
Jéssica Veiga-Matos ${ }^{1}$, Fernando Remião ${ }^{1}$, Ana Morales ${ }^{2}$ \\ ${ }^{1}$ UCIBIO/REQUIMTE, Laboratório de Toxicologia, Departamento de Ciências Biológicas, Faculdade de Farmácia, \\ Universidade do Porto, Rua de Jorge Viterbo Ferreira, 228, 4050-313, Porto, Portugal. \\ ${ }^{2}$ Unidad de Toxicología, University of Salamanca, Spain; Group of Translational Research on Renal and Cardiovascular \\ Diseases; Instituto de Investigación Biomédica de Salamanca, Edificio Departamental, Salamanca, Spain.
}

\begin{abstract}
Transporters are large membrane proteins, which control the passage of various compounds through biological membranes. These proteins are divided into uptake and efflux transporters and play an important role in the toxicokinetics of many endobiotics and xenobiotics. The uptake transporters facilitate the absorption of these compounds from the blood into the proximal tubular cells, while the efflux transporters eliminate these compounds into tubular fluid (urine). Overall, the uptake is performed by the superfamily solute carrier (SLC) transporters, which are, mostly, located in the basolateral membrane. The organic anion transporters (OATs; SLC22), the organic cation transporters (OCTs; SLC22), the organic cation/carnitine transporters (OCTNs), and the organic anion transporting polypeptides (OATP; SLC21/SLCO) are some examples of uptake transporters of the SLC superfamily. On the other hand, the superfamily ATP-binding cassette (ABC) transporters carry out the elimination of the substances through the apical membrane of the proximal tubular cells. The multidrug resistance proteins 1 (MDR; $\mathrm{ABCB}$ ), the multi resistance protein (MRP2; $\mathrm{ABCC}$ ) and the breast cancer resistance protein (BCRP, ABCG) along with the multidrug and toxin extrusion (MATE), which is an SLC transporter, carry out the substance efflux of the cell, However, uptake transporters seem to be more efficient than efflux transporters, leading to an accumulation of compounds in proximal tubular cells and, consequently, to renal damage. The accumulation of compounds can also occur due to variations in the number of transporters that exist due to differences in sex, age, genetic polymorphisms and epigenetics. Furthermore, some substances can inhibit, induce or, eventually, activate these transporters, with consequent drug-drug interactions (DDIs) as a result of alterations on the toxicokinetics of xenobiotics, leading to an increase of their accumulation and, consequently, to renal damage. These compounds may be exogenous, such as antibiotics, antivirals, cisplatin, metals, herbicides, mycotoxins and drugs; or endogenous, like uric acid, bile acids, bilirubin conjugates and conjugated steroids. Thus, in this review, we will focus on the accumulation of exogenous compounds due to variations on renal transporters and the consequent biological effects caused by them.
\end{abstract}

Corresponding author: Fernando Remião, Faculdade de Farmácia, Rua de Jorge Viterbo Ferreira, 228, 4050-313, Porto, Portugal; Phone number: 00351220428598; E-mail address: remiao@ff.up.pt

Received, August 10, 2020; Revised, September 24, 2020; Accepted, September 25, 2020; Published, September 26, 2020

\section{INTRODUCTION}

Kidney is the excretory organ responsible for the excretion of various intact compounds and/or products of metabolism from circulation $(1,2)$. In this process, two steps occur: glomerular filtration, where ultrafiltrate originates, and tubular secretion (Figure 1) $(1,3)$. In the glomerulus the blood is filtered, entering through the afferent arteriole and exiting through the efferent arteriole. Renal function can be assessed by determining the glomerular filtration rate (2). The rate of glomerular filtration can be affected by several factors, such as physical exercise; pregnancy; the presence and severity of kidney diseases; time of day; protein consumption; administration of antihyper- tensives; and extracellular fluid status, which can cause alterations to blood flow resulting in changes in toxicokinetics and plasma levels of xenobiotics $(4,5)$.

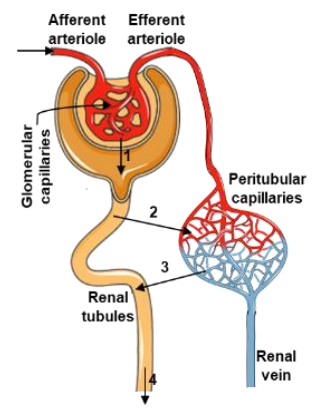

Figure 1. Renal excretion of the xenobiotics.

1. Glomerular filtration;

2. Reabsorption;

3. Tubular secretion;

4. Excretion. 
The compounds present in the ultrafiltrate are released into the urine or reabsorbed back into the bloodstream $(1,3)$. Thus, overall the kidney retains essential nutrients (e.g., glucose, amino acids) and expels metabolic waste products (e.g., creatinine, uric acid) and xenobiotics (e.g., antiviral drugs and antibiotics) (6). However, all of these substances may still be retained in tubule cells depending on various factors, such as: physicochemical properties, reactivity, and susceptibility to binding to intracellular components (1).

Tubular secretion is mostly performed in the proximal tubule $(1,7)$ and is carried out in two phases: (1) uptake of the compounds from the peritubular fluid into the tubular cell through the basolateral membrane and (2) efflux of these same compounds out of the cell into luminal fluid through the apical membrane $(3,8)$. The majority of the molecules travel this course with the help of transporters present in the basolateral and apical membranes $(1,8)$ and not by passive diffusion, since the molecules are very often hydrophilic as a result of being charged at physiological $\mathrm{pH}$. Thus, these transporters control the input and output molecules, being a key part of the process for the physiology of tubular epithelial cells (9). Their acting as gatekeepers, due to their interaction with xenobiotics, makes this transport a totally different process from the passive process of glomerular filtration (6). The various carriers enrolled in tubular secretion have different requirements according to their location in the proximal tubule, the specificity of the substrate and the transport mechanism itself (3). The speed at which a molecule is transported depends on several factors, such as: transporter capacity, gene expression level, Michaelis constant, substrate concentration and transport competition/inhibition by other xenobiotics $(10,11)$.

A xenobiotic is characterized by its toxicokinetics, which refers to the movement of the compound throughout the organism from the moment it is absorbed until it is excreted. Generally, the absorption, distribution, metabolism, excretion and transport (ADMET) phases are considered (12). Metabolism is often classified as phase I or II (functionalization or conjugation, respectively). More recently, the terms phase 0 and III have been associated with the uptake and efflux transport, respectively, thus characterizing the complete movement of a molecule in a given cell (Figure 2) $(10,13)$. Transporters have a significant role in ADMET since they act as regulators (14).

In this review, we intend to focus on the renal transporters, outlining the different types and classes of carriers present in this organ. In addition, we will also describe the different xenobiotics that cause nephrotoxicity, in which the transporters seem to have a role.

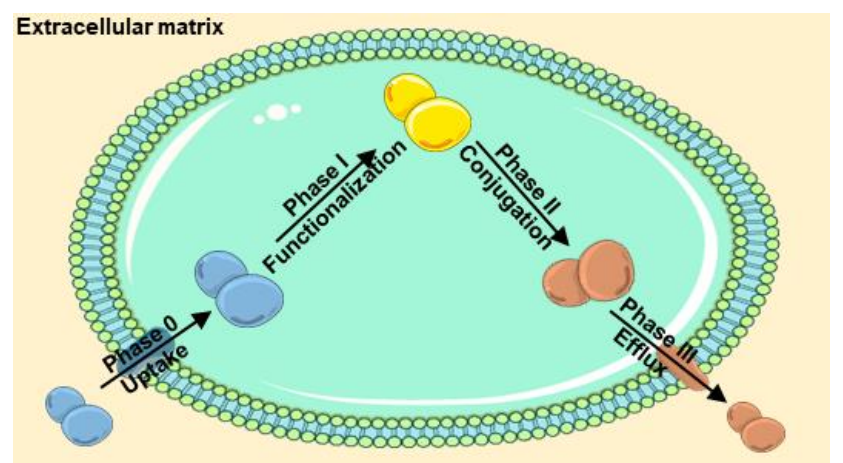

Figure 2. Molecule movement in a given cell, including the phase 0 - III.

\section{RENAL TRANSPORTERS}

Transporters are large proteins incorporated into the cell membranes, and are expressed in several cells of the major organs with functions of absorption and elimination, specifically on their epithelia, such as the liver, intestine, kidney, brain, testes and placenta, sites of high importance with regard to the evaluation of the disposition of xenobiotics (15). These membrane proteins serve to control the uptake and efflux of the most varied molecules, from toxins to drugs and metabolites (16). In addition to that major function, they also serve to regulate the movement of small endogenous molecules such as key metabolites, signaling molecules, vitamins, antioxidants (e.g., uric acid) and some hormones (17).

In the kidney, uptake transporters aid the passage of the compounds from blood or ultrafiltrate into the proximal tubular cells, while efflux transporters excrete them back into the blood or urine (6). These transporters are expressed in greater amounts in the basolateral and apical membranes of the proximal tubular epithelial cells (18). There are two super families that represent the most expressed transporters in the basolateral and apical membranes: the solute carrier (SLC) transporters superfamily (molecular weight of 40-90 kDa), which assure, mostly, the cellular uptake of the compounds from the blood on the basolateral membrane; and the adenosine triphosphate (ATP)-binding cassette (ABC) transporters superfamily (molecular weight of 140 $180 \mathrm{kDa}$ ), which facilitate the efflux to the tubular lumen on the opposite side of the cell, the apical membrane (Figure 3) $(16,18,19)$. In this way, it is important to note that the tubular secretion of a xenobiotic always involves at least one transporter of each type (18). 


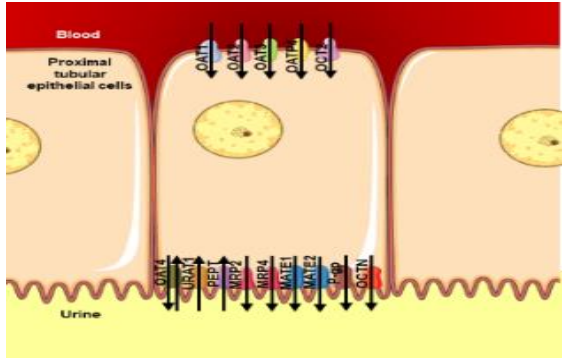

Figure 3. Representation of the location and transport direction of the renal transporters.

\section{Uptake transporters}

The SLC transporters is a large family of transmembrane proteins that share $20-25 \%$ of their homologous sequence (15), and includes more than 400 members grouped in 52 families, which perform various cellular functions cooperating with other proteins (19). This superfamily has members with high abundance in various organs (liver, kidney, bloodbrain barrier) that have important functions in the toxicokinetics of various compounds (Table 1; Figure 4) (20).

Table 1. Location and substrates of the main uptake transporters in proximal tubular cells.

\begin{tabular}{lll} 
Transporter & Gene & Location \\
\hline AT1 & $S L C 22 A 6$ & Basolateral membrane
\end{tabular}

\section{Substrates}

PAH, antivirals, NSAIDs, antibiotics, diuretics, folate, $\alpha$-ketoglutarate, cyclic nucleotides, prostaglandins, gut microbial metabolites, uremic toxins, vitamins, dietary compounds, uric acid, mercurial

\section{'AT2}

$S L C 22 A 7$

'AT3

'AT4

RAT1

CT2

$S L C 22 A 2$

'ATP4C1 SLCO4Cl Basolateral membrane

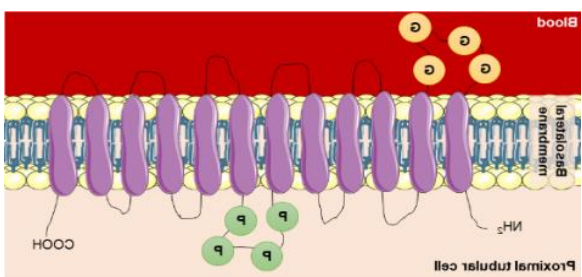

Figure 4. Representation of the constitution of a SLC transporter.
PAH, antivirals, salicylate, acetylsalicylate, prostaglandin E2, dicarboxylates, glutamate, uric acid

Conjugated sex steroids, vitamins, aristolochic acid and other plant-derived metabolites (e.g., flavonoids), ochratoxir. A, anti-viral, anti-cancer, antibiotics, anti- hypertensive, anti inflammatory drugs

Uric acid, diuretics, sulfated steroids, NSAIDs, antihypertensives, prostaglandins

Uric acid

Metformin, cisplatin, atenolol, histamine $\mathrm{H} 2$ blockers, HIV protease inhibitors, b-blockers, some platinum compounds, calcium channel blockers, antiarrhythmics, antimalarials, catecholamines, choline, acetylcholine, serotonin, creatinine

Glycosides (digoxin and ouabain), thyroid hormones (triiodothyronine [T3] and thyroxine), cyclic adenosine monophosphate (cAMP), methotrexate, sitagliptin, estrone 3 sulfate, chenodeoxycholic acid, and glycocholic acid

Valproic acid, cephaloride, ergothioneine, verapamil, quinidine and gabapentin 
There are various mechanisms that SLC transporters use to perform their uptake function, such as facilitated diffusion, ion coupling, and ion exchange, which can be promoted by a gradient created by the $A B C$ transporters (15). In this way, the uptake of the xenobiotics can be performed in a facilitated diffusion, in which the SLC transporters function as uniporters (passive transport, according to the concentration gradient). On the other hand, SLC transporters can perform secondary active transport, simultaneously transporting $\mathrm{Na}^{+}$in (symport) or out (antiport) of the cell (10).

\section{Organic anions transporters}

The organic anion transporters (OATs) carry out the passage of small organic anions across the membranes against their concentration gradient using $\mathrm{a} \mathrm{Na}^{+}$ gradient maintained by $\mathrm{Na}^{+} / \mathrm{K}^{+}$-ATPase. OATs are expressed in the renal proximal tubule and have a significant role in the tubular secretion of various compounds (4), including steroid hormones, biogenic amines (15), drugs [e.g., antibiotics, antivirals, diuretics, nonsteroidal anti-inflammatory drugs (NSAIDs)] (21), environmental toxins and toxicants (e.g., mycotoxins and pesticides) and natural products in herbs (e.g., flavonoid conjugates, gentisic acid) (6). OAT1 and OAT3 have particular importance, since they are predominantly expressed in the basolateral membrane of proximal renal tubules, although both are expressed in other tissues in the body (15). Due to their pharmaceutical importance, they are the beststudied SLC families from the viewpoint of drug handling (22).

OAT1, expressed by the $S L C 22 A 6$ gene, is one of the most expressed transmembrane proteins in the adult kidney, located in the basolateral membrane of the cells of the proximal tubule (23), playing an important role in the clearance of a wide variety of xenobiotics (24). The expression of this transporter in the kidney increases during gestation and after birth (23). This transporter was originally cloned from mice in 1996 as the novel kidney transporter (NKT), and it was then suggested and confirmed that it is an organic transporter (i.e., the "classical" p-aminohippurate (PAH) transporter) or organic anion transporter $(3,21,23)$. Substrates of OATs include PAH, antivirals, nonsteroidal anti-inflammatory drugs (NSAIDs), antibiotics, diuretics, folate, $\alpha$ ketoglutarate, cyclic nucleotides, prostaglandins, gut microbial metabolites, uremic toxins, vitamins, dietary compounds, uric acid, mercury conjugates, and other toxins (23).

OAT2, a protein expressed by the $S L C 22 A 7$ gene, has greater expression in the liver and kidney (23), in which it is present in the basolateral membrane (18).
This transporter has a greater expression in the developing mouse embryo (lung, developing bone/cartilage, kidney, liver) (23). OAT2 has affinity for some anionic compounds like salicylate, acetylsalicylate, prostaglandin E2, dicarboxylates, glutamate, uric acid and $\mathrm{PAH}$, as well as some antivirals $(18,23)$. In addition, it addresses the transport of guanine nucleotide (cGMP) -related compounds and cGMP itself (23).

OAT3 is the most expressed transporter in the renal proximal tubule in humans, being expressed by the $S L C 22 A 8$ gene $(4,23)$. Unlike OAT1, it is also located on the membrane of the distal tubular cells. On the other hand, besides being found in greater quantities, it is also present in other places like the choroid plexus, the brain capillary endothelium, and the retina (23). OAT1 and OAT3 have some common substances as substrates $(3,23,24)$; however, these have higher affinity for one transporter or the other. Another difference between OAT1 and OAT3 is that OAT3 has higher affinity for carrying cations than OAT1 (23), whereas OAT1 shows higher affinity for carrying PAH $(3,21)$. Furthermore, unlike OAT1, OAT3 can transport sulfate and glucuronide conjugates (3). Substrates of OAT3 include conjugates of signaling sex steroids, vitamins and other plantderived metabolites (e.g., flavonoids), aristolochic acid, ochratoxin A $(22,23)$, drugs (e.g., anti-viral, anticancer, antibiotics, anti-hypertensive, antiinflammatory) (4).

OAT4, the transporter expressed by the SLC22A11 gene, has its greatest expression in the placenta followed by the kidney (23). Unlike the other OATs, this is expressed in the apical membrane of the cells, which suggests participation in the secretion and reabsorption of the respective organic anions from the urine back into the proximal tubular cells, like uric acid and diuretics $(6,18,25)$. This carrier has substrates including sulfated steroids, NSAIDs, antihypertensives, prostaglandins, and uric acid (23). OAT5 (SLC22A19) is expressed on the apical membrane of the proximal tubular cells, specifically on the S2 and S3 segments. OAT10 (SLC22A13) is spread throughout the body, having the highest amounts in the kidney, small intestine and colon (23). Besides the transport of organic anions, OAT10 transports uric acid across the apical membrane (25). OAT6 and OAT7 are not present in the kidney. OAT6 $(S L C 22 A 10)$ is highly expressed in nasal epithelia and has weaker expression in the testis, whereas OAT7 (SLC22A9) is specific to the liver (23).

Another member of the SLC22A family is URAT1, expressed by the SLC22A12 gene on the apical membrane of the proximal tubular cells, which reabsorbs the urate of the urine, replacing it with 
several organic anions $(18,25,26)$. Urate is a metabolism product of endogenous and exogenous purines like DNA/RNA and food derivatives, respectively. In urine, urate is in deprotonated form, uric acid, due to the low $\mathrm{pH}$ of this fluid (25). Secretion of this compound occurs through a complex process of glomerular filtration, reabsorption and secretion. Normally, approximately $90 \%$ of the glomerular-filtered urate is reabsorbed back into the bloodstream with the aid of URAT1, and approximately $10 \%$ is renally excreted $(27,28)$. URAT1 is an electroneutral organic anion exchanger, functionally, and is the typical 12-transmembrane domain protein, structurally, as its homologs of its family SLC22 (25).

\section{Organic cations transporters}

Organic cations transporters (OCT) are the subclass of transporters belonging to the SLC22 family, which aid the transport of organic cation by electrogenicfacilitated diffusion, independently of sodium and chloride ions gradient $(10,29)$. In the kidney, OCTs cooperate with multidrug and toxin extrusion (MATE) proteins to mediate transepithelial transport of organic cations. In the human body, there are OCT1, OCT2 and OCT3. The first two are very similar as they share $70 \%$ of their protein sequence, whereas OCT3 only shares $50 \%$ with the others (29). The following substances have already been classified as substrates of OCTs: dexpramipexole, lamivudine, metformin, pilsicanide, sepantronium bromide and tiotropium (30).

OCT1, expressed by the SLC22Al gene, is located in greater amounts in hepatocytes. However, it is also found in the kidney, small intestine, colon, lung, brain, heart, skeletal muscle, peripheral leukocytes, adrenal gland, mammary gland, immune cells and adipose tissue (29). In the kidney, this transporter is located on the apical membrane of the proximal and distal tubules, performing tubular reabsorption of compounds such as metformin (18).

OCT2 is expressed in greater amounts in the basolateral membrane of the renal proximal tubule cells by the $S L C 22 A 2$ gene. In smaller amounts, it is also expressed in the brain, lung, small intestine, thymus, placenta and the inner ear (29). Of all OCTs, it is the one that is found in greater quantities in the kidney, performing the main transport of organic cations in this organ at the expense of inside negative membrane potential $(1,31)$. To evaluate the function of this transporter, tetraethylammonium (TEA) and 1methyl-4-phenylpyridinium (MPP) are used as model substrates (18). The major transporter, OCT2 has as its substrate a wide variety of xenobiotics, such as metformin (specific for this carrier), cisplatin, atenolol, histamine $\mathrm{H}_{2}$ blockers, HIV protease inhibitors, b-blockers, some platinum compounds, calcium channel blockers, antiarrhythmics and antimalarials $(1,18,29)$; as well as endogenous substances, such as: catecholamines, choline, acetylcholine, serotonin and creatinine (18).

OCT3, expressed by the $S L C 22 A 3$ gene, has a significantly larger distribution than the remaining transporters of this class, being present in skeletal muscle, placenta, salivary glands, heart, brain, adrenal gland, trachea, small intestine, and uterus. Their location in the cells depends on the tissue (29). This carrier is also found in the kidney, but its role in nephrotoxicity is still unknown (1).

\section{Organic anion transporting polypeptides}

The organic anion transporting polypeptide (OATP; SLCO) family includes sodium- independent organic anion transporters that are present in various tissues such as the liver, kidney, intestines, and brain (32). These types of carriers have the specification for substrates with amphipathic characteristics that are normally bound to albumin (a plasma protein) (33), including endogenous compounds, like bile acids, thyroid hormones, sulfated and glucuronidates hormones, and xenobiotics, such as rifampicin, methotrexate, antidiabetics, and statins $(15,32)$.

In the kidney, OATP4C1 (SLCO4Cl) is the most expressed transporter, being present in large quantities in the basolateral membrane of the proximal tubular cells $(1,32)$. This transporter has high affinity for various substances, performing urinary secretion of glycosides (digoxin and ouabain), thyroid hormones (triiodothyronine [T3] and thyroxine), cyclic adenosine monophosphate (cAMP), methotrexate, sitagliptin, estrone 3-sulfate, chenodeoxycholic acid, and glycocholic acid $(18,20,32)$. OATP2A1 is located throughout the human body, including ocular tissues and gastroduodenal mucosa, and has prostaglandin transporters (PGT) (10).

\section{Organic carnitine/cation transporters}

Organic carnitine/cation transporters novel (OCTN) is a subfamily of SLC transporters, which includes OCTN1, OCTN2 and OCTN3; however, the latter is not present in the human body (34). OCTNs perform their transport function depending on the substrate, cation/proton exchange, cation/cation exchange, sodium-dependent and sodium-independent transport mechanism (10).

OCTN1 and OCTN2 share $76 \%$ of their protein sequence and both are located on the apical membrane of proximal renal tubular cells $(1,34)$. OCTN1, expressed by the gene $S L C 22 A 4$, transports carnitine and some xenobiotics, such as valproic acid, 
cephaloride, ergothioneine, verapamil, quinidine and gabapentin $(1,18,23)$.

OCTN2 transports carnitine and its derivatives by making an electrogenic cotransport of $\mathrm{Na}^{+}$. Both endogenous and exogenous carnitine have affinity for this carrier since the esterification of this compound does not affect its recognition. Carnitine has as its essential functional groups the ammonium and the carboxylate. Thus, substrates with these functional groups are also transported by OCTN2, and therefore, carriers of this carrier are precursors of carnitine, like $\gamma$-butyrobetaine, and derivatives, such as acetylcarnitine and acyl-carnitines. The binding site of OCTN2 is large, whereby this carrier has significant ability to carry and/or interact with a wide variety of xenobiotics (34), such as translocate choline, verapamil, emetine, cefepime, valproic acid (18). In addition, OCTN2 causes the efflux of carnitine and its derivatives, which can be driven by a favorable gradient of these molecules. However, this transport is not controlled by the $\mathrm{Na}^{+}$movement, but by the $\mathrm{pH}$ of the medium (alkaline $\mathrm{pH}$ will cause the carrier to have a higher activity) (34).

\section{Efflux transporters}

The ABC superfamily of transporters can be found in a variety of organs, such as the intestine, liver, kidney, heart, lung, brain, placenta and testis, and are very important in ADMET of various endogenous and exogenous compounds since they assure various physiological functions including protection from toxic substances due to their export capacity, metabolite transport and cell signaling $(19,35)$. More than 100 transporters/channels belong to this superfamily. In humans, $49 \mathrm{ABC}$ transporters belonging to seven families involved in the transport of xenobiotics have been identified (Table 2; Figure $5)$. The ABC transporters are responsible for phase III, which results in cellular elimination for various fluids, like feces, urine and bile (12). In order to move the compounds through the cell membrane, ABC transporters need the energy obtained through the hydrolysis of ATP. Thus, these transmembrane proteins can export the compound, reducing its cellular concentration. This process is called the primary active transport, since, in addition to spending ATP, it is done against the concentration gradient $(10,12,15)$.

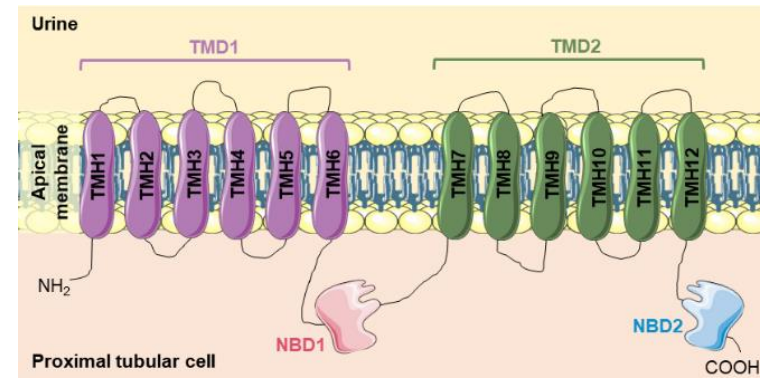

Figure 5. Representation of the constitution of an ABC full-transporter, with two transmembrane domains (TMD) and two nucleotide binding domains (NBD).

Generally, $\mathrm{ABC}$ transporters consist of two parts: (1) nucleotide binding domains (NBD), which contain one pair of ATP binding domains inside the membrane, in the cytoplasm; and (2) two sets of transmembrane domains (TMD), which usually have six membrane spanning $\alpha$-helices. The NBD owns three conserved domains: Walker A and B domains, found in all ATP-binding proteins, and a signature $\mathrm{C}$ motif, specific to each $\mathrm{ABC}$ transporter, located upstream of the Walker B site. These transporters, also called pumps, transport the molecules in only one direction (usually out of the cell's cytoplasm). Therefore, the movement is generally performed from the inner leaflet of the phospholipid bilayer to the outer leaflet or to an acceptor molecule. However, the

Table 2. Location and substrates of the main efflux transporters in proximal tubular cells.

\begin{tabular}{lccl}
\hline Transporter & \multicolumn{1}{c}{ Gene } & \multicolumn{1}{c}{ Location } & \multicolumn{1}{c}{ Substrates } \\
\hline MRP1 & $A B C C 1$ & Apical membrane & $\begin{array}{l}\text { GSH, cysteinyl leukotrienes, glucuronide and } \\
\text { sulfate conjugates, anthracyclines, Vinca } \\
\text { alkaloids, and antivirals }\end{array}$ \\
MRP2 & $A B C C 2$ & Apical membrane & $\begin{array}{l}\text { GSH and glucuronide conjugates, leukotrienes, } \\
\text { methotrexate, ochratoxin A }\end{array}$
\end{tabular}

Table 2 Continues ... 
P-gp $\quad A B C B$

BCRP

$A B C G 2$

MATE1

SLC47A1

Apical membrane

Apical membrane

chemotherape nucleoside drugs, nucleoside analogs, fluorophores, conjugated anions estrone3- sulfate, flavonoids, folates (folic acid), riboflavin (vitamin B12), porphyrins

Histamine $\mathrm{H} 2$ receptor antagonist, cimetidine, the antidiabetic agent, metformin, and the herbicide, paraquat

MATE2-K $\quad S L C 47 A 2$

Apical membrane

Metformin, cimetidine, antibiotics, oxiliplatin described morphology does not correspond to all $\mathrm{ABC}$ transporters, since these can be: i) full transporters containing two NBDs and two TMDs (at least); or ii) half transporters containing one NBD and one TMD, which may aggregate as homodimers or heterodimers in order to functionalize (Figure 5) (12,36).

\section{Multidrug resistance proteins}

Multidrug resistance proteins (MRP) are one of the most important subfamilies to remove xenobiotics from proximal tubular cells to urine, from hepatocytes to bile, or from intestinal epithelium to intestinal lumen (37). These proteins acquired this name because of their role in resistance to drugs when present in tumor cells, since they remove a wide variety of anticancer drugs (18). This class of carriers belongs to the ABCC family, which includes nine MRPs (37), and are considered fullsize transporters (38). Of these, MRP1, MRP2 and MRP4 have been studied the most with regard to drug toxicity (15). In general, MRPs are efflux pumps for organic anions, like beta lactam antibiotics, as well as for glucuronide and glutathione (GSH) conjugates, such as acetaminophen-glucuronide and arsenic-GSH (1).

MRP1, expressed by the $A B C C 1$ gene, is present in large quantities in several organs: the lung, testes, kidney, skeletal and cardiac muscles, placenta, and macrophages. To perform its function, MRP1 uses GSH in different ways: i) as a co- substrate together with hydrophobic compounds; ii) as a substrate, only in the presence of some xenobiotics (e.g., verapamil and dietary flavonoids); iii) an enhancer of MRP1-Mediated Transport of glucuronidated and sulfated conjugates, without being co-transported itself (37). In this way, MRP1 has as substrates various endogenous substances, such as oxidized glutathione, cysteinyl leukotrienes, glucuronide and sulfate conjugates, and also xenobiotics, like anthracyclines, Vinca alkaloids, and antivirals (15).

MRP2 is expressed by the $A B C C 2$ gene on the apical membrane of various tissues, such as hepatocytes, kidney proximal tubules, small intestine, colon, gall bladder, segments of bronchi, and placenta. This carrier is present only on the apical side of the cells, which is in accordance with its efflux function of turning compounds into extracellular fluids, like bile, urine, and intestinal fluid (37). The regulation of the expression and activity of MRP2 is well characterized and can occur in one of three ways: i) endocytic retrieval/exocytic insertion (occurs within minutes); ii) translational regulation (within several hours); or iii) transcriptional regulation (within days) (33). P-Aminohyppurate (PAH), a classical substrate used to characterize organic anion transport, is also substrate of MRP2 (20), in addition to a wide variety of endogenous substances as well as various exogenous compounds (15). MRP2 has as substrates conjugated and unconjugated organic anions, including glutathione conjugates, glucuronide conjugates, leukotrienes, methotrexate and ochratoxin A (33).

MRP4, expressed by the $A B C C 4$ gene, may be present on the apical or basolateral side, depending on the type of cell in which it is present. In the 
kidney, it is present in the apical membrane of the proximal tubular epithelium. However, it is found in the basolateral membrane in various tissues (e.g., hepatocytes, pancreatic duct epithelial cells, choroid plexus epithelial cells) (37). Like MRP2, MRP4 has a high affinity for the transport of organic anions, including PAH; however, MRP4 is expressed in greater amounts and has even higher affinity $(1,20)$. Substrates of MRP4 include various endogenous compounds, like guanosinemonophosphate (cGMP) and adenosinemonophosphate (cAMP), GSH, bile acids, folate, eicosanoids, urate, prostaglandins and conjugated steroids $(15,20,37)$. In addition, it also carries several xenobiotics, such as cephalosporin antibiotics, cytotoxic agents (methotrexate and 6mercaptopurine), and several NSAIDs $(15,33)$.

MRP3 and MRP6 are present in the membranes of the distal and proximal tubular cells, respectively. On the other hand, MRP5 and MRP79 are not expressed in the kidney (37).

\section{Multidrug resistance}

P-glycoprotein (P-gp), also called multidrug resistance 1 (MDR1), is expressed by the $A B C B 1$ gene and belongs to the superfamily of $A B C$ transporters (12). This protein is synthesized in the endoplasmic reticulum as a glycosylated intermediate with a molecular weight of 150-170 $\mathrm{kDa}$, with the carbohydrate moiety being further modified in the Golgi apparatus prior to the export to the cell surface $(12,39)$. Like others ABC transporters, MDR owns two TBDs and two NBDs, being a full-transporter. In this way, the substrates of P-gp bind to a binding site intracellularly. Then, following phosphorylation of the protein with ATP spending by hydrolysis, a flip-flop movement occurs in which the substrate is extruded to the luminal side. The return to the initial state of the protein takes place by dephosphorylation $(12,39,40)$.

P-gp is present in the apical membrane in numerous cell types, like epithelial cells of the intestine, bile ducts, kidney proximal tubules, and endothelial cells of the blood-brain barrier, which shows the importance of its localization in the accomplishment of its function $(1,10,15)$. Its physiological role of secreting endogenous and exogenous metabolites (through phase III-mediated transport) influences the toxicokinetics of several compounds $(11,12)$.

P-gp carries a wide variety of compounds, being a non-specific transporter. P-gp has some substrates in common with MRP1 and MRP2, more specifically cytostatic agents (39). The substrates of
P-gp vary greatly in size, structure, and function, ranging from small molecules, such as organic cations, carbohydrates, amino acids, and some antibiotics, to macromolecules such as polysaccharides and proteins, which is due to P-gp being a protective protein against various substances (12). Several drugs are considered substrates of P-gp, among them: anticancer agents, cardiac glycosides (e.g., digoxin), b-adreno receptor antagonists, $\mathrm{Ca}^{2+}$ channel blockers, HIV protease inhibitors, steroids, immunosuppressants, antiemetic drugs, antibiotics, antimicrobial, antiretrovirals, lipid lowering agents, histamine $\mathrm{H}_{1-}$ receptor antagonists, phenobarbital, phenytoin, and others $(1,10,18)$.

\section{Breast cancer resistance protein}

Breast cancer resistance protein (BCRP) is expressed by the $A B C G 2$ gene, and is the second member of the ABCG family belonging to the $A B C$ superfamily (38), and was discovered in a multidrug-resistant breast cancer cell line (41). Like the efflux transporters already mentioned (MRP and MDR), BCRP is not very specific to substrates nor for inhibitors (42). On the other hand, unlike MRP and MDR, BCRP is a half-transporter [only six transmembrane spanning helices (10)], functioning as a homodimer that transports the substrates actively through the membrane $(38,41)$.

This carrier is widely distributed throughout human organs such as the GI tract, liver, kidney, central nervous system, mammary tissue, testes, ovaries, adrenal glands, and placenta $(10,38,42)$. Their distribution shows that, in fact, BCRP protects cells against xenobiotics. In the kidney, it is present in the apical membrane of the proximal tubular cells, which proves its intervention in the elimination of xenobiotics influencing their toxicokinetics $(38,42)$. The location of the BCRP, as well as some substrates, overlaps with those of the MRP and P-gp which suggests all of these efflux pumps complement each other to perform their function of eliminating compounds (41).

BCRP carries a wide variety of different compounds together structurally and functionally (41). Among the endogenous substrates present are urate, cholesterol, plant sterols and phospholipids $(10,25)$. It also helps the remaining pumps in the transport of GSH and glucuronide conjugates. However, BCRP is predominantly an efflux carrier for xenobiotics, like chemotherapeutics (mitoxantrone, topotecan), anthracycline drugs (daunomycin, doxorubicin, epirubicin), nucleoside analogs (lamivudine), fluorophores (rhodamine 123, Hoechst 33342), conjugated anions estrone-3- 
sulfate, flavonoids (genistein), folates (folic acid), riboflavin (vitamin B12), and porphyrins (heme) $(10,15,38,41)$.

\section{Multidrug and toxic extrusion}

Multidrug and toxic extrusion (MATE) transporters belong to the SLC superfamily, yet function as efflux transporters because they remove their substrates out of the cells. For this, they take advantage of the oppositely directed proton gradient, acting as secondary active transporters. As efflux transporters, they are located on the apical membrane of cells such as MRP, P-gp and BCRP, which belong to the $\mathrm{ABC}$ superfamily. It is possible to observe that SLC and ABC transporters work together for the renal excretory mechanism to function correctly (43). MATE transporters are constituted by 13 transmembrane helices (TMH), of which twelve are required for the transport of compounds and one is required for protein turnover $(43,44)$. In humans, MATE is encoded by the SLC47A gene and include two members: MATE1, MATE2 and MATE2-k (a splice variant of MATE2). In the kidney, MATE transporters control the exit of the organic cations through the membrane into urine $(16,45)$, in electroneutral exchange for protons [sustained by the membrane $\mathrm{Na}^{+} / \mathrm{H}^{+}$exchanger and the V-type proton ATPase (18)], since they are located on the apical membrane of the proximal tubular cells facing the tubular lumen (29,31). It can be concluded that there is an OCT-MATE vector transport that excludes various xenobiotics; however, if the balance between these transporters is interrupted there may be accumulation of these toxics in the proximal tubules $(1,43)$. Substrates of MATE overlap with OCT substrates since these cooperate in their activity $(43,44)$. In general, substrates of MATE are considered substances with cationic character, weak bases with positive charge, zwitterions or even anions of molecular weight ranging from 50 to over 500 (43). For example, MATE proteins transport MPP+ and TEA antibiotics (cephalexin and cephradine), antidiabetics (metformin), histamine $\mathrm{H}_{2}$-receptor antagonist cimetidine, herbicide paraquat, platinum agents and endogenous substances (creatinine, the vitamin thiamine, corticosteroids, cimetidine $(18,44)$.

MATE1 is encoded by the SLC47Al gene, being highly expressed in the kidney and liver; however, it is also present in the adrenal gland, skeletal muscle, testis and first trimester placenta $(10,43)$. MATE1 has only one isoform, which is 570 amino acids in length (29). This transporter excretes the organic cations that uptake the basolateral membrane of the proximal tubular cells by OCT1 and OCT2 (20). Typically, histamine $\mathrm{H}_{2-}$ receptor antagonist, cimetidine, the antidiabetic agent, metformin, and the herbicide paraquat are considered as substrates of MATE1 (1).

MATE2 is expressed by the $S L C 47 A 2$ gene (15); and has three isoforms: the full-length isoform MATE2 (602 amino acids), MATE2-K (566 amino acids) and MATE2-B (220 amino acids). Both are functional, whereas MATE2-B possesses no transport activity (29). MATE2 shares 94\% amino acid similarity with its MATE2-K isoform. MATE1 shares $48 \%$ and $51 \%$ similarity in the sequence of amino acids with MATE2 and MATE2-K, respectively. In humans, MATE2 and MATE2-K are specifically expressed in the kidney, more specifically in proximal tubule cells, but they are also detectable in various tissues, like the placenta $(29,43)$. MATE2-K shares overlapping substrates with MATE1 including cimetidine and metformin (1). However, some substrates may have greater affinity for one rather than another. For example, cephalexin, cephradine, fexofenadine and the oxazolidinone antibiotic are primarily transported by MATE1, whereas oxaliplatin is specifically transported by MATE2-K (10).

\section{Other transporters}

Peptide transporters (PEPT) are expressed in kidney and intestinal cells, with two isoforms: PEPT1, encoded by the $S L C 15 A 1$ gene, and PEPT2, expressed by the $S L C 15 A 2$ gene. Their function is to perform uptake of compounds, such as peptidergic b-lactam antibiotics and various other drugs, such as ACE-inhibitors and peptidomimetic drugs (10). However, like OAT4, they may be present in the apical membrane of the renal cells participating in the reabsorption of some organic anions (18).

Sulfate-anion antiporters 1 (SAT1), encoded by the $S L C 26 A 1$ gene, are located in the basolateral membrane of proximal tubular cells. SAT1 regulates sodium-dependent movement of sulfate across the membrane in exchange for anions, like $\mathrm{OH}$ or HCO3. However, some organic anions may also be substrates of SAT1. Among the substrates are sulfated steroid hormones (cortisone sulfate, cortisol sulfate, estradiol sulfate) and some bile acids (33).

Sodium-phosphate transporters (NPT) are also expressed in the kidney in three isoforms: NPT1, NPT2 and NPT4. NPT1, expressed by the SLC17A1 gene on the apical membrane, regulates the efflux of organic anions by harnessing the potential of internal negative membrane. NPT1 substrates are 
transport PAH, urate, benzylpenicillin, beta-lactam antibiotics, estradiol-17-b-glucuronide $(18,20)$. NPT2 is highly expressed in the apical membrane of the proximal tubules, regulating the resorption of resorbed phosphate (20). NPT4 is also present in the apical membrane of the proximal tubules, being expressed by the SLC17A3 gene. This performs the transport of various organic anions, such as PAH, Ochratoxin A. In addition, it also makes the efflux of urate (1).

In addition to the members of the superfamily SLC shown, there are still equilibrative nucleoside transporters (ENTs) and concentrative nucleoside transporters (CNTs), which are involved in the transport of nucleosides and nucleoside analogs from urine. Expressed in the apical membrane are CNT1 (SLC28A1), CNT2 (SLC28A2), CNT3 (SLC28A3), ENT1 (SLC29A1) and ENT4 (SLC29A4), carrying out the urinary reuptake of nucleosides. On the other side of the cell, on the basolateral membrane, ENT1 (SLC29A1) and ENT2 (SLC29A2) are present, facilitating the efflux of the nucleotides to the blood flow, completing the reabsorption process. However, these transporters can also aid secretion of these substances because of their capacity of bidirectional transport (18). ENT4, also known as a plasma membrane monoamine transporter (PMAT), has a high specificity for organic cations, like OCTs and MATE. Thus, PMAT also performs an electrogenic transport using the inside- negative physiological membrane potential as a driving force, which can be further stimulated by lowering the $\mathrm{pH}$. In addition to the kidney, PMAT is also present in the brain, heart, small intestine and liver $(18,29)$.

\section{Interindividual variability}

As mentioned, SLC and ABC transporters play a key role in the absorption, distribution and elimination of xenobiotics. Interindividual variability of these transporters can lead to differences in therapy and even adverse drug reactions $(46,47)$. This phenomenon may be due to several factors or a combination of factors. Among them are: non-genetic factors, including age, sex, ethnicity, kidney diseases or medication; genetic variations; and epigenetic mechanisms, such as DNA methylation, histone modifications, or miRNAs $(46,48,49)$.

Regarding the sex of the individual, women have chronic kidney disease more often than men (50). This is due to hormonal differences but also to the different levels of enzymes and proteins that each sex has (51). On the other hand, it has also been shown that females have greater expression of certain transporter coding genes (23).

Age also affects the individual variability of renal function since renal function may decrease due to: i) exacerbation of newly developing renal disease; ii) increased susceptibility to AKI from chemical exposures; iii) toxic accumulation of renally cleared therapeutic agents (51). For example, the expression of SLC transporters varies greatly with age, starting at mid-gestation and gradually increasing until birth. After birth, the expression increases rapidly until adolescence and, then, remains stable during adulthood $(22,47)$. On the other hand, a decrease in the ability to transport some drugs was also found, which is associated with aging. Thus, the kidney of an older individual will be more susceptible to acute injury leading to ischemic injury or drug-induced toxicity. Joseph and his group showed that 13 of the 27 drug transporters studied exhibited an age-bias with individuals aged 50 years or above $(\geq 50)$ showing dominance, and seven exhibited an age-bias with individuals aged below 50 years $(<50)$ showing dominance in mRNA expression. These researchers also studied transporters among different ethnicities, showing that 22 of the 27 transporter genes studied had higher expression in African Americans and two of the 27 transporter genes studied, like OAT2 (SLC22A2), exhibited higher expression in African Americans compared to European Americans. These differences may occur due to different diets, medical practices, or genetic differences. The findings of this study show that these three factors interfere together in the response to xenobiotics (48).

In addition to the non-genetic factors, genetic polymorphisms are an important factor that alters the probability of the individual having acute or chronic kidney diseases from chemical exposure. Several carrier proteins show genetic variations that can lead to the accumulation of xenobiotics within the renal cells, by increasing the activity of the uptake transporters and reducing the activity of the efflux transporters, which leads to nephrotoxicity $(14,51)$. Thus, mutations in the members of the SLC and $A B C$ superfamilies lead to different individual responses to xenobiotics, which may be termed toxicogenetics $(20,51)$. OATs, like the other transporters, are regulated by chemical inducers, hormones, nuclear receptors, transcription factors and diseases (22,35). For example, OATs are associated with metabolic abnormalities and diseases, such as kidney fibrosis and kidney failure, since they decrease OAT1, OAT2 and OAT3 expression (17). Genetic polymorphisms, more 
specifically single nucleotide polymorphisms (SNPs) in the URAT1 gene, cause renal hyperuricemia and hypouricemia $(18,23)$. SLC22A1, a gene encoding OCT1, is highly polymorphic and its expression and function is commonly influenced by several factors (46). Genetic variations in the formation of OCT also cause changes in the intracellular concentrations of metformin and cisplatin, for example $(9,20)$. On the other hand, there are 28 SNPs in different ethnic populations, of which four SNPs present alterations in their in vitro function of OCT2 (SLC22A2) (31). OCTN also showed to be affected by polymorphisms, since an alteration of gabapentin clearance was observed. In addition, it may also cause primary systemic carnitine deficiency, a recessive inherited disorder linked with an increased risk of hypoketotic hypoglycemia, Reye's syndrome (18). Several studies have observed the importance of altered expression of MATE in the interindividual variability of metformin response (44). A decrease in MATE activity causes a decrease in the efflux of metformin, leading to lactic acidosis $(9,16,45)$.

Regarding mutations in the ABC superfamily, they are also associated with diseases such as cystic fibrosis, persistent hyper insulinemic hypoglycemia of infancy, Dubin-Johnson syndrome, Stargard disease and Tangier disease (12). Genetic polymorphisms in MRP2, for example, cause accumulation of its substrates in the renal cells (15), such as methotrexate. Accumulation of lamivudinetriphosphate and tenofovir are associated with MRP4 (18). Mutations in the formation of MRP6 represent the molecular basis of the connective tissue disease pseudoxanthoma elasticum (PXE) (37). Polymorphisms affecting MDR1 are associated with lower digoxin renal clearance, modified efficacy and nephrotoxicity of chemotherapeutics, antivirals and immunosuppressants, cyclosporine (due to impaired apical efflux) (18). In addition to these, $A B C B 1$ polymorphisms contribute to the alteration of the disposition and, consequently, to the interindividual variability in response to various drugs, like morphine and other opioids (e.g., methadone) (47). Other issues may emerge due to genetic changes in $A B C G 2$, which encodes the $\mathrm{BCRP}$, among them are hyperuricemia (since it also causes urate efflux); accumulation of its substrates due to low efflux $(26,38)$.

Genetic changes in transporter expression may also be due to epigenetic phenomena, including covalent modifications of DNA and histones, chromatin folding, and regulatory noncoding RNAs (microRNAs). The mechanisms of epigenetic regulation are processes that alter transcription without altering the DNA sequence. Figure 6 presents some examples of epigenetic changes $(23,42,46)$.

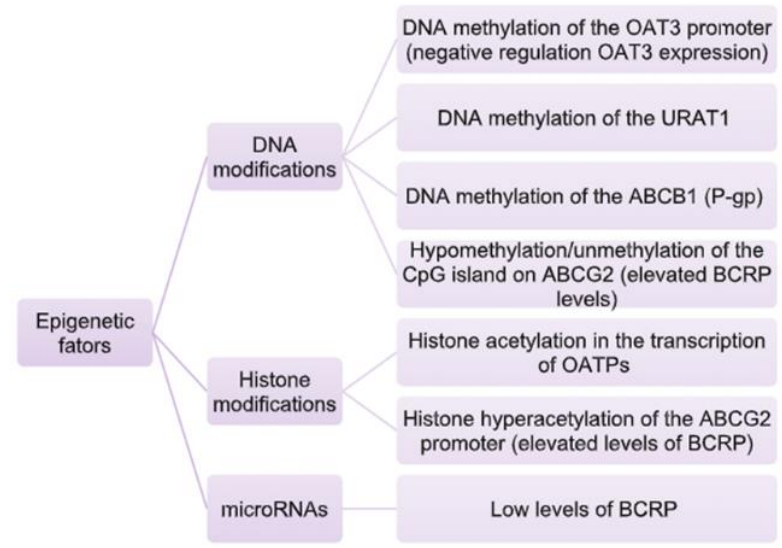

Figure 6. Some examples of epigenetic changes.

\section{NEPHROTOXIC AGENTS}

Renal transporters regulate the secretion/reabsorption of the many compounds, hence, play a huge role in the nephrotoxicity $(9,13,51)$. Uptake transporters are frequently more efficient than efflux ones, resulting in a higher concentration of xenobiotics within the proximal tubular cell (Figure 7) $(9,52)$. Xenobiotic may be exogenous, such as heavy metals, herbicides, mycotoxins and drugs (1), or endogenous, like uric acid, indole derivatives, prostaglandins, bile acids, bilirubin conjugates and conjugated steroids (23). This review will focus on exogenous nephrotoxic agents.

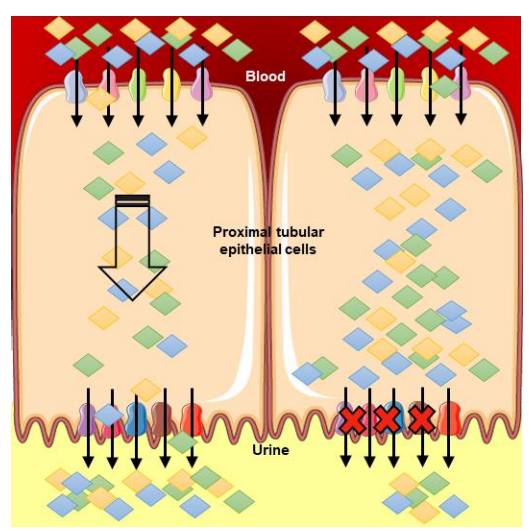

Figure 7. Representation of the xenobiotics accumulation in proximal tubular cells due to inefficient transport by efflux transporters.

\section{Therapeutic agents}

Of the xenobiotics that cause nephrotoxicity we can subdivide the group known as medicines. These 
specific drugs are used in therapy with different functions, among them: antibiotics, antivirals, anticancer, etc. (Table 3 ). However, some can cause kidney damage due to their intracellular accumulation.

\section{Antibiotics}

Most antibiotics are acids or weak bases and, as such, only the water-soluble may be directly excreted by the kidney (53).

The beta-lactam antibiotics include penicillin, cephalosporins, and carbapenems, which are characterized as cyclic dipeptides containing lactam rings that react with bacterial carboxypeptidases to prevent cell wall synthesis (1). The renal toxicity caused by cephalosporin, for example, is directly related to its intratubular concentration, which depends on the administered dose and the balance between the uptake and efflux transporters. The accumulation of this drug leads to direct toxicity caused by beta-lactams rings. Cephalosporins that cause nephrotoxicity in therapeutic dosages are cephaloridine and cephaloglycin, which are no longer used (54). The cephaloridine accumulation in renal proximal tubule cells leads to acylate proteins, and/or induces lipid peroxidation (1).

Another type of antibiotic is aminoglycosides, which are widely used in the treatment of infections caused by Gram-negative bacteria and bacterial endocarditis. This drug has a cationic structure with different numbers and distribution of amino groups, which affects the toxicity caused in the tissues where it accumulates. Thus, there is nephrotoxicity due to the accumulation of aminoglycosides in the kidney (55), because its excretion is performed by protein-mediated transport almost exclusively by this organ $(53,56)$. Despite renal damage, aminoglycosides continue to be used because they are chemically stable, have low resistance, are cheap, have a fast-bactericidal effect, and have synergy with beta-lactam antibiotics (55). An example of an aminoglycoside is gentamicin, transported by OCT2, which is normally used against microorganisms resistant to other medicines such as, for example, pseudomonas $(54,56)$. Like the remaining aminoglycosides, cytotoxicity of gentamicin occurs at sites where it accumulates,

Table 3. Transporters used and diseases caused by some nephrotoxic therapeutic agents

\begin{tabular}{|c|c|c|c|}
\hline Drug Class & Examples & Transporter & Disease \\
\hline \multirow[t]{6}{*}{ Antibiotics } & Cephalexin & MATE1, MRP4 & $\begin{array}{l}\text { Acute interstitial nephritis, } \\
\text { glomerulonephritis }\end{array}$ \\
\hline & Cephaloridine & OAT1, OAT3, OCTN1 & $\begin{array}{l}\text { Acute interstitial nephritis, } \\
\text { glomerulonephritis }\end{array}$ \\
\hline & Gentamicin & OCT2 & Tubular cell toxicity \\
\hline & Levofloxacin & $\begin{array}{l}\text { OATP1A2, MATE1, } \\
\text { MATE2-k, P-gp }\end{array}$ & $\begin{array}{l}\text { Acute interstitial nephritis, crystal } \\
\text { nephropathy }\end{array}$ \\
\hline & Penicillin G & OAT1, OAT2, BCRP & $\begin{array}{l}\text { Acute interstitial nephritis, } \\
\text { glomerulonephritis }\end{array}$ \\
\hline & Vancomycin & Unknown & Tubular cell toxicity \\
\hline \multirow[t]{4}{*}{ Antivirals } & Acyclovir & $\begin{array}{l}\text { OAT1, OAT2, OAT3, } \\
\text { PEPT1, MATE1, MATE2- } \\
\text { K }\end{array}$ & $\begin{array}{l}\text { Acute interstitial nephritis, crystal } \\
\text { nephropathy }\end{array}$ \\
\hline & Adefovir & OAT1; MRP1 & Tubular cell toxicity \\
\hline & Cidofovir & OAT1, OAT3 & Tubular cell toxicity \\
\hline & Tenofovir & OAT1, OAT3, MRP4, P-gp & Tubular cell toxicity \\
\hline Anticancer & Cisplatin & $\begin{array}{l}\text { OCT2, MATE1, MATE2- } \\
\text { K, P-gp }\end{array}$ & $\begin{array}{l}\text { Chronic interstitial nephritis, tubular } \\
\text { cell toxicity }\end{array}$ \\
\hline
\end{tabular}

Table 3 continues .... 


$\begin{array}{lll}\begin{array}{l}\text { Immunosuppre } \\ \text { ant }\end{array} & \text { Cyclosporine } & \text { P-gp } \\ \text { NSAIDs } & \text { Aspirin } & \text { OAT1 }\end{array}$

\begin{abstract}
Decreased glomerular filtration rate, hypertension

Acute interstitial nephritis, chronic interstitial nephritis, intraglomerular hemodynamics alteration
\end{abstract}

as in proximal, distal and collecting tubular cells (55). When there is accumulation of gentamycin in a cell, it enters the lysosomes leading to lipid peroxidation and binding to the phospholipids of the lysosomal membrane, which results in lysosomal phospholipidosis. Subsequently, gentamicin will release into the cytosol where it will interact with the mitochondria. This interaction results in: i) apoptosis; ii) interruption of the respiratory chain and ATP production; iii) oxidative stress by increasing superoxide anions and hydroxyl radicals; or/and finally iv) cell death $(54,55)$. In the absence of ATP, necrosis occurs. On the other hand, it acts on the endoplasmic reticulum inhibiting protein synthesis; interfering with the translational accuracy and the correct posttranslational protein folding (55).

Fluoroquinolones, like levofloxacin, are another class of antibiotics that cause nephrotoxicity. Although these cases are rare, they are described in the literature, showing crystalluria, interstitial nephritis, and acute renal failure associated with levofloxacin (57). Other authors report other nephrotoxicity symptoms such as hypersensitivity vasculitis, interstitial nephritis, and acute renal failure (58). Vancomycin belongs to the group of glycopeptide antibiotics and is commonly used in the treatment of resistant infections, such as methicillin-resistant Staphylococcus aureus (MRSA), coagulase-negative staphylococci and Enterococcus faecium. However, that it causes nephrotoxicity is attributed to its impurity ("Mississippi mud"). Studies suggest that this antibiotic induces the formation of free radicals and oxidative stress in proximal renal tubular cells (59). The mechanism by which vancomycin causes nephrotoxicity depends on the process of energydependent reabsorption (transport from the blood to the tubular cell across the basolateral membrane) (53). There is intra lysosomal accumulation, as in the mechanism of gentamicin (59). The risk of nephrotoxicity increases when the concentration of vancomycin increases and also when there is concurrent treatment with aminoglycosides (53).

\section{Antiviral drugs}

Antiviral drugs are medications used against infections caused by viruses, such as cytomegalovirus, herpes virus and retrovirus (1). However, the more potent these drugs are the greater the frequency of induced nephrotoxicity. Renal tubular toxicity often occurs due to the concentration of the antiviral, which is due to an uptake increase by OAT1 and/or a decrease in the elution by the MRP2. Some antiviral agents cause cell necrosis or apoptosis, such as acyclovir and ganciclovir, while others, like cidofovir and tenofovir, cause cell damage without death, resulting in Fanconi-like syndrome and crystal formation (60).

Nucleotide analogs are structurally-related to endogenous nucleotides and include cidofovir, adefovir, and tenofovir. This structure allows them to incorporate the viral DNA by reverse transcriptase. However, they have the great limitation of accumulating in the kidney and may lead to renalrelated side effects, such as Fanconi syndrome, progressive declines in kidney function, diabetes insipidus, and tubular dysfunction, or acute tubular necrosis possibly through direct mitochondrial damage. Cidofovir, adefovir, and tenofovir are transported by OAT1 and OAT3 (1).

Adefovir, 9-(2-phosphonomethoxyethyl) adenine, is a nucleotide monophosphate analogue that integrates into the pro-viral DNA chain, causing premature DNA chain termination by blocking incorporation of the subsequent nucleotide. This drug is an antiretroviral agent for the treatment of infection with the human immunodeficiency virus (HIV) (61). Cidofovir is an antiviral nucleoside phosphonate analogue that has activity against the DNA of several viruses, like the herpes virus, adenovirus, papillomavirus, polyomavirus and poxvirus. The selective proximal tubular toxicity of cidofovir results from the OAT1 presence, which controls the uptake of cidofovir and leads to selective accumulation and toxicity (62). Adefovir and cidofovir present similar toxicity, having as main proximal tubule pathology acute kidney injury, as a result of acute tubular necrosis and Fanconi's syndrome $(63,64)$. These issues result from a disruption of proximal tubular mitochondrial function caused by these drugs. An altered mitochondrial function, along with other conditions, leads to a deficit in adenosine triphosphate production, impaired cell function, and cell injury and/or death (63). Tenofovir is an acyclic nucleotide analogue reverse transcriptase inhibitor structurally similar to adefovir and cidofovir, which has its usual substrate viral RNA-directed DNA 
polymerase and is a weak inhibitor of mammalian DNA $\alpha-$ and $\beta$-polymerases and mitochondrial DNA $\gamma$ - polymerase. It was the first drug in the treatment of HIV to be approved by the FDA (Food and Drug Administration), but has also been approved for the treatment of chronic hepatitis B. Tenofovir causes proximal tubular cell injury, resulting in partial or complete Fanconi syndrome, or acute or chronic kidney disease. As in previous antivirals, mitochondria is a target for toxicity (65).

In addition to nucleotide analogs, there are other antiviral agents, such as acyclovir and ganciclovir, which are also substrates of uptake transporters OAT1, OAT2 and OCT1 and transporters of efflux MRP2 and MRP4 (1). Acyclovir, for instance, has crystal nephropathy as a major mechanism, which results in acute kidney injury (66).

\section{Cisplatin}

Cisplatin (cis-diamminedichloroplatinum II) was the first platinum-based antineoplastic to be discovered and it is currently used in the treatment of solid tumors (67). Its mechanism of action is to affect several pathways of signal translation that will lead to the induction of apoptosis (68). In the kidney, the influx of cisplatin is performed by OCT2 and copper transporter 1 (SLC31AI) and basolateral transporters of proximal tubular cells, whereas efflux is performed by MATE1, MRP2 and P-gp, apical transporters $(9,12)$. The combined activity of these transporters determines the inexistence of cisplatin accumulation, which will correlate with nephrotoxicity (24).

Once inside the cells, cisplatin has several effects that lead to cell death: i) DNA damage: this drug binds to adjacent purine bases altering the secondary structure of DNA, which inhibits its function template and DNA replication; ii) cytoplasmic organelle dysfunction: with endoplasmic reticulum stress and mitochondrial dysfunction; iii) apoptotic pathways both caspase-dependent and receptor-mediated death; iv) oxidative stress: with formation of reactive oxygen species and depletion of GSH, an antioxidant; or/and finally v) inflammation: mediated via tumor necrosis factor and other chemokines $(68,69)$.

\section{Cyclosporine A}

Cyclosporine A (CsA) is a lipophilic cyclic polypeptide isolated from the fungus Tolypocladium inflatum and is used as an immunosuppressant drug in the control of organ transplantation and autoimmune disorders. This drug inhibits the synthesis of interleukin 2, which leads to the suppression of secondary synthesis of various cytokines, suppressing the activation and proliferation of $\mathrm{T}$ cells (70). CsA is also used to reduce the risk of relapse of the disease in children with frequently recurring nephrotic syndrome (FRNS) (71). However, this drug causes nephrotoxicity with a relationship between the existence of this toxicity in renal transplant patients and the metabolism of CsA. In fact, adverse effects in the kidney are observed, such as a decrease of glomerular filtration rate and hypertension, which are related to vasoconstriction of glomerular afferent arterioles. In addition, several ROS, like the superoxide radical, are involved in cyclosporineassociated nephrotoxicity (70). CsA is a substrate of P-gp, being excreted from renal proximal tubular cells by this protein (72).

\section{Nonsteroidal anti-inflammatory drugs}

The nonsteroidal anti-inflammatory drugs (NSAIDs) are a broad class of drugs that includes analgesic, antipyretic and anti-inflammatory, which are widely used globally. NSAIDs inhibit cyclooxygenase $(\mathrm{COX})$, blocking prostaglandin, prostacyclin, and thromboxane production $(73,74)$. This enzyme has two isoforms: COX-1, expressed in all tissues, and COX-2, expressed and activated only in response to inflammation (75). Nonselective NSAIDs inhibit both isoforms while selective agents inhibit COX-2 much more than COX-1, reducing the adverse effects caused by COX-1 (76).

In the kidney, NSAIDs are transported by OAT3 from the blood into proximal tubule cells (10). Despite the benefits of inhibiting prostaglandin synthesis, there are also detrimental effects at the renal level, since they are associated with increased blood pressure and renal blood flow, glomerular filtration and sodium excretion (77). COX activity is decreased in a normal blood flow state. However, if this decreases, the enzyme synthesis will increase to protect cells against renal ischemia and hypoxia. If NSAIDs are administered when the cell is in this state, it will alter the balance of activity between renal vasoconstrictors and vasodilators. Thus, renal ischemia with loss of glomerular filtration will be promoted (78). NSAIDs react immunologically leading to acute renal failure, by acute interstitial nephritis and acute tubular necrosis $(79,80)$. Thus, the direct toxicity of NSAIDs in renal tubular cells involves: loss of polarity, loss of tight junctions, loss of cell substrate adhesion, exfoliation of viable cells from tubular basement membrane, aberrant renal cellcell adhesion, altered gene expression, cellular dedifferentiation and necrosis or apoptosis. Tubular necrosis may occur due to depletion of cellular ATP stores, reduced activity of membrane transport pumps, cell swelling, increase in intracellular free calcium, activation of phospholipases and proteases, 
glycine depletion and plasma and subcellular membrane injury. These adverse effects rarely occur, but their frequency has increased due to the high prescription of these drugs (81).

\section{Others xenobiotics}

In addition to the therapeutic agents, there are other xenobiotics that cause nephrotoxicity that can be consumed in exposure to the environment as by exposure in the diet (Table 4).

\section{Aristolochic acid}

Aristolochic acid (AA) is the major alkaloid of the herbal species Aristolochia and is used commonly as an ingredient of various Chinese herbal medicines. Since it is associated with the development of nephrotoxicity, it is also known as "Chinese herb nephropathy" (78). On the other hand, AA is also present in several dietary compounds that have been associated with Balkan endemic nephropathy (22). AA causes renal and hepatic reductive metabolism to form reactive aristo-lactams, which react with DNA originating adducts. AA and its metabolite are transported by OAT1, OAT2 and OAT3, leading to accumulation in the renal proximal tubular cell where production of reactive oxygen species (ROS) and reactive nitrogen species (RNS) occurs. This phenomenon leads to a cell-cycle arrest, changes in mitogen-activated protein kinase signaling, apoptosis, and activation of inflammatory mediators, which is consistent with the formation of DNA adducts and oxidative stress-induced DNA damage $(51,78)$

\section{Fluoride}

Inorganic fluoride $(\mathrm{F})$ is an environmental agent, which in some countries is added in low quantities to drinking water with the intention of preventing dental caries (51). However, there is evidence that accumulation of this element causes various adverse effects in human tissue (82). The kidney, as the main organ in excretion of $\mathrm{F}$, undergoes toxicity by accumulation of renal tubular cells, resulting in oxidative stress and peroxidation of the cell membrane lipids $(83,84)$. Fluoride induces various

Table 4. Transporters used and diseases caused by the several nephrotoxic xenobiotics.

\begin{tabular}{|c|c|c|c|}
\hline \multirow{2}{*}{\multicolumn{2}{|c|}{$\begin{array}{l}\text { Xenobiotic } \\
\text { Aristolochic acid }\end{array}$}} & Transporter & Disease \\
\hline & & OAT1, OAT2, OAT3 & $\begin{array}{l}\text { "Chinese herb nephropathy", Balkan endemic } \\
\text { nephropathy }\end{array}$ \\
\hline \multicolumn{2}{|c|}{ Fluoride } & Unknown & Tubular toxicity \\
\hline \multirow[t]{3}{*}{ Metals } & Arsenic & $\begin{array}{l}\text { GLUT1, GLUT5, } \\
\text { OATP2B1, MRP2, } \\
\text { MRP4, P-gp, MATE }\end{array}$ & Fanconi syndrome, tubular cell toxicity \\
\hline & Cadmium & $\begin{array}{l}\text { OCT2, MATE1, } \\
\text { MATE2-K }\end{array}$ & $\begin{array}{l}\text { Renal dysfunction by Fanconi-type syndrome, } \\
\text { nephrolithiasis, and hypercalciuria }\end{array}$ \\
\hline & Mercury & OAT, MRP2, BCRP & Tubular cell toxicity \\
\hline \multirow{2}{*}{\multicolumn{2}{|c|}{$\begin{array}{l}\text { Ochratoxin A } \\
\text { Paraquat }\end{array}$}} & OAT & Tubular cell toxicity \\
\hline & & OCT, MATE; P-gp & $\begin{array}{l}\text { Renal dysfunction by acute renal failure and, then, } \\
\text { acute oliguric renal failure }\end{array}$ \\
\hline
\end{tabular}

changes in cellular dynamics, such as: i) inhibition of protein synthesis; ii) production of $\mathrm{ROS}$, like $\mathrm{O} 2$, and depletion of SOD2; iii) alteration of the cellular metabolism; iv) activation of cellular signal transducing systems; and v) apoptosis. Histological changes caused by $\mathrm{F}$ are: necrosis of glomeruli and tubules; atrophic glomeruli and glomerular capsule; tubular dilatation; and tubular damage (resulting from ischemic or nephrotoxic injury) $(82,84)$.

\section{Metals}

Renal transporters are also involved in nephrotoxicity caused by metals (85). Arsenic (As) is a heavy metal present in the Earth's crust and is considered to be an environmental contaminant, which can be found in its inorganic (iAs; arsenite, arsenate) or organic form (arsenobetaine, arsenocholine and arsenosugars) $(51,86)$. Exposure to As is associated with the development of tumors in various organs, like the skin, lung, bladder, liver and kidney, as well as cardiovascular diseases, hypertension, peripheral artery disease and diabetes mellitus (86). Arsenic is excreted in the urine through the kidney, where it accumulates, inducing tubulointerstitial nephritis and acute tubular necrosis characterized by hypercalciuria, albuminuria, 
nephrocalcinosis, and necrosis of the renal papillae (Orr and Bridges, 2017). After being absorbed into the kidney, iAs is methylated and the transport of iAs as well as its methylated forms play a key role in the accumulation of metal in proximal tubular cells and consequently in nephrotoxicity. In the basolateral membrane, As uptake is made by glucose transporters 1 and 5 and OATP2B1 (although its role in the uptake of this metal is unclear). In the apical membrane, the efflux of As is performed by MRP2, MRP4, P-gp and MATE (51). Once within the proximal tubular cells, iAs causes: i) depletion of the intracellular GSH; ii) activation of the caspase-3 and -9 signaling pathways; iii) increases in the expression of interleukin-6 and interleukin-8; or/and finally iv) activation of the p-53 apoptotic pathway. These processes lead to an increased production of ROS and other free radicals, inflammation, and apoptosis. In addition, there is an interruption of oxidative phosphorylation leading to a decrease in sodium, phosphate and glucose transport, which is characterized as Fanconi syndrome (phosphaturia, glucosuria and low- molecular weight proteinuria) (86).

Cadmium (Cd) is a heavy metal to which we are exposed in various forms, such as tobacco smoke, contaminated foods, Ni-Cd batteries, fuel combustion, sewage and certain medicinal herbs, and is considered an environmental and occupational toxicant (51). The human body does not have an efficient mechanism of excretion of $\mathrm{Cd}$ and, as such, it accumulates and has a long half-life of 10 to 30 years. Exposure to $\mathrm{Cd}$ leads to various diseases such as neurological diseases, renal dysfunction, pulmonary complications, diabetes, cancer, immunosuppression, bone disorders, and cardiovascular diseases (1). Within the group of organs in which $\mathrm{Cd}$ accumulates, the kidney is recognized as the most toxic target. Several proteins contribute to the accumulation of $\mathrm{Cd}$ in renal cells, including metallothioneins (MTs), zinc transporters, calcium transporters, divalent metal-ion transporter1, OCTs, MATE, and additional cadmium-binding proteins containing thiol groups. That is, $\mathrm{Cd}$ circulates in blood bound to albumin for the most part, but also to thiol-containing groups such as GSH and L-cysteine (Cys). Once in the liver, $\mathrm{Cd}$ stimulates the formation of MTs, developing Cd-MT complexes that are released into the bloodstream and later absorbed into the kidney (88). Of the already mentioned carriers, OCTs (more specifically, OCT2) and MATE are particularly interesting since they are capable of uptake and efflux of $\mathrm{Cd}$ from tubular cells, respectively, by eliminating $\mathrm{Cd}$ from the human body and attenuating its effects on other organs $(87 ; 88)$.
The mechanism of toxicity of Cd involves provoking the formation of ROS and thus generating oxidative stress; cell apoptosis, and glomerular contraction $(1,88)$. On the other hand, $\mathrm{Cd}$ can mimic some essential metals, such as calcium, disturbing the homeostasis of electrolytes and some metabolites, which can result in Fanconi-type syndrome, nephrolithiasis, and hypercalciuria (51).

Another heavy metal worth mentioning is Mercury $(\mathrm{Hg})$. This heavy metal has 3 forms: elemental $\mathrm{Hg}(\mathrm{Hg} 0)$; $\mathrm{Hg}$ inorganic (which includes mercurous mercury $\left[\mathrm{Hg}^{+}\right]$and mercuric mercury $\left[\mathrm{Hg}^{2+}\right]$ and organic $\mathrm{Hg}$, where methylmercury (MeHg) protrudes (89). All forms of $\mathrm{Hg}$ are nephrotoxic; however, exposure to $\mathrm{Hg}^{2+}$ has the greatest nephrotoxic effects, with the kidney being the site of greatest accumulation of $\mathrm{Hg}^{2+}$. Thus, $\mathrm{Hg} 0$ and $\mathrm{MeHg}$ are neurotoxic, whereas inorganic mercury salts are nephrotoxic. $\mathrm{Hg}$ binds to one or more thiol-containing biomolecules, such as GSH, Cys, N-acetylcysteine (NAC) and albumin. Its binding to GSH, by itself, already decreases the cellular antioxidant capacity against oxidative stress and inflammation $(87,89)$. OATs uptake $\mathrm{Hg}^{2+}$ and $\mathrm{MeHg}$ from the blood to proximal tubular cells, whereas the efflux to the urine is done by MRP2 and BCRP, which are responsible for their accumulation. The strong binding to proteins mentioned above contributes to the mechanism of action of this metal, since it can develop cell injury pathways, resulting in cell death (1).

\section{Ochratoxin A}

Ochratoxins are one of the important groups of mycotoxins. Ochratoxin A (OTA) is the most prevalent of this group, being produced by several species of fungi from Penicillium and Aspergillus genera that contaminate animal feed and food worldwide $(90,91)$. OTA is structurally different from Ochratoxin B and $\mathrm{C}$. The major renal diseases that OTA causes are Balkan endemic nephropathy (BEN), chronic interstitial nephritis, and karyomegalic interstitial nephritis. The mechanisms of action of OTA include: i) inhibition of protein synthesis; ii) interference with metabolic pathways involving phenylalanine; iii) disruption of calcium homeostasis; iv) promotion of membrane lipid peroxidation; v) inhibition of mitochondrial respiration; and vi) DNA damage and the modulation of gene expression (90). In addition, excretion of OTA into the urine is mainly by tubular secretion, presumably via the OAT system, which causes accumulation of this compound in the tubular cells and, consequently, nephrotoxicity $(1,92)$. 


\section{Paraquat}

Paraquat (PQ) is a non-selective contact herbicide used globally as the desiccant and defoliant in a variety of crops. PQ is involved in thousands of fatal poisonings from accidental and intentional exposure (93). This small divalent cation, after oral administration, is rapidly distributed accumulating in large concentrations in the kidney, liver, and lung. Pneumotoxicity is the major cause of mortality, since the lung possesses the polyamine uptake system (SLC22), which results in PQ accumulating here in greater quantities. Furthermore, $\mathrm{PQ}$ is also a nephrotoxic agent, as the kidney is the site of its excretion, subjecting the proximal tubules in particular to damage $(1,94)$. In the kidney, the influx of PQ is performed by OCT while the efflux is done by the MATE transporter and P-gp $(12,94,95)$. The mechanism of PQ toxicity is based on entering redox cycling in the presence of oxygen, leading to ROS and, consequently, oxidative stress. In PQ intoxications it is common to observe acute renal failure, and acute oliguric renal failure in more severe intoxications (96). In the event of kidney dysfunction, this herbicide will not be properly eliminated from the human body, leading to greater accumulation in other organs, such as the lung, leading to pulmonary toxicity, multi-organ failure and death (97).

\section{Drug-drug interactions}

Both in therapeutics and in cases of intoxication, multiple xenobiotics can be administered simultaneously, triggering drug-drug interactions (DDIs). DDIs may result in greater or lesser amounts of the xenobiotic, in the event of inhibition or induction, respectively (98). Thus, when two drugs, transported by the same carrier, are co-administered, DDIs can occur in one of two ways: i) competitive inhibition, where drugs compete for the same binding site to the carrier, binding to the one with the highest affinity; or ii) non-competitive inhibition, where one of the drugs binds to a non-transporting site by altering the conformation of the protein (18). In therapeutics, compounds have been studied that are able to inhibit or induce the activity of these transporters, since DDIs may alter pharmacokinetics and pharmacodynamics of other compounds that are co-administered $(21,99)$. On the other hand, it is important to evaluate the specificity of the transporters of the SLC and ABC superfamilies (Tables 5 and 6), which regulate the transport of various drugs that may cause nephrotoxicity due to their accumulation $(23,100)$.

A classic example of DDIs is the interaction between probenecid and $\beta$-lactam antibiotic, in which there is an increased exposure to penicillin due to inhibition of OAT1 and OAT3 $(15,99)$. However, if NSAIDs are co-administered with antiviral agents, such as adefovir, they may inhibit antiviral uptake by attenuating its nephrotoxic effects (23). On the other hand, probenecid began to be used to increase the concentrations of other drugs to maximize the therapeutic effect (6). OCTs and OCTNs are also carriers that can mediate DDIs since, for example, OCTN1 is inhibited by quinidine, levofloxacin and verapamil $(18,20)$. As previously mentioned, OCT and MATE cooperate in the excretion of compounds, so nephrotoxicity may result from changes in both (29). For example, the $\mathrm{H}_{2}$-receptor antagonist cimetidine and the antimalarial agent pyrimethamine inhibit MATE ten times more than OCT2. Thus, when co-administered with substrates of MATE, they will cause DDIs with increased drug exposure (44).

P-gp is inhibited by protease inhibitors, statin calcium antagonists, immunosuppressants, antimycotic agents and many other substances, whereas its activity is induced by rifampicin, cytostatic agents, corticosteroid hormones and other molecules. All these compounds may alter the elimination of digoxin, quinidine, cyclosporine, clarithromycin and ritonavir by this carrier protein (12). On the other hand, P-gp is induced by many drugs, including dexamethasone, rifampicin, doxorubicin (95). Table 7 summarizes some examples of P-gp inducers, which increase its expression in the brain, liver, intestine and kidney.

P-gp activity can also be increased by activation, where compounds, including Hoechst-33342 and rhodamine 123 , bind to this transporter altering their conformational structure and, consequently, stimulating the transport of substrates that use the other binding site. Thus, this transporter contains, at least, two cooperative sites for compounds to bind to and be transported (101). This activation mechanism is a more rapid process than P-gp induction since that increases P-gp transport function without interfering with the protein expression levels, unlike what happens in the induction of P-gp where the inducer increases the expression of this protein (95). This phenomenon of induction/activation can be harnessed in therapy. Some studies show that P-gp inducers, like doxorubicin, can increase P-gp activity in Caco-2 cells, leading to a more efficient transport of PQ to extracellular matrices and a decrease in PQ intracellular accumulation. Silva et al were able to decrease the toxicity of PQ using di-hydroxylated xanthonic derivatives as inducers and activators of $\mathrm{P}$ gp (95). Lopes et al characterized thioxanthone derivatives, particularly

chiral 
aminatedthioxanthones, successively as activators of P-gp (102). In the future, it would be interesting to study inducers and activators of P-gp through specific models of the kidney, since it could be a detoxifying system against xenobiotics, including the nephrotoxic ones. As suggested by del Moral and his group, the P-gp overexpression in renal tubular cells decreases the nephrotoxicity caused by cyclosporine A (103). Another medication that also causes nephrotoxicity is cisplatin. Thus, it would be possible to use this drug in a safer form in tumor therapy if we can eliminate it more quickly and efficiently from renal tubular cells by activation/induction of P-gp, reducing the side effects of this drug (Figure 8).

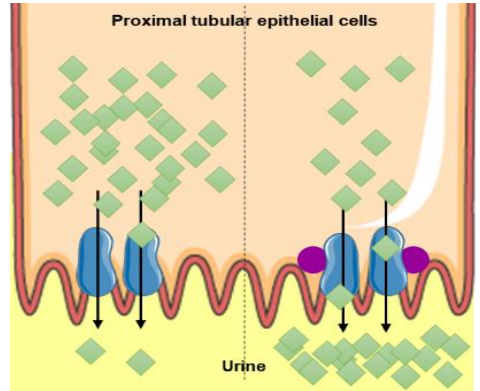

Figure 8. Representation of the difference between transport performed by $\mathrm{P}$-gp with/without activation.

Table 5. Inhibitors and substrates affected by DDIs of the uptake transporters (Giacomini et al., 2010; Huneycutt et al., 2018; Pochini et al., 2019).

\begin{tabular}{|c|c|c|}
\hline Transporter & Substrate (affected by the inhibitor) & Inhibitor \\
\hline OAT1 & $\begin{array}{l}\text { PAH, adefovir, cidofovir, zidovudine, lamivudine, } \\
\text { zalcitabine, acyclovir, tenofovir, ciprofloxacin, } \\
\text { methotrexate }\end{array}$ & Probenecid, novobiocin \\
\hline OAT3 & $\begin{array}{l}\text { Oestrone-3-sulphate, non-steroidal anti-inflammatory } \\
\text { drugs, cefaclor, ceftizoxime, furosemide, bumetanide }\end{array}$ & Probenecid, novobiocin \\
\hline OCT1 & $\begin{array}{l}\text { Tetraethylammonium, N-methylpyridinium, metformin, } \\
\text { oxaliplatin }\end{array}$ & $\begin{array}{l}\text { Quinine, quinidine, } \\
\text { disopyramide }\end{array}$ \\
\hline OCT2 & $\begin{array}{l}\text { N-Methylpyridinium, tetraethylammonium, metformin*, } \\
\text { pindolol, procainamide, ranitidine amantadine, amiloride, } \\
\text { oxaliplatin, varenicline }\end{array}$ & $\begin{array}{l}\text { Cimetidine, pilsicainide, } \\
\text { cetirizine, testosterone, quinidi }\end{array}$ \\
\hline URAT1 & Uric acid & Probenecid, lesinurad \\
\hline OCTN1 & $\begin{array}{l}\text { Amisulpiride, cytarabine, entecavir, metmorfin, pregabalin, } \\
\text { gapapentin, 5-aminosalicylic acid, camptothecin }\end{array}$ & Sulpiride \\
\hline \multirow[t]{2}{*}{ OCTN2 } & Amisulpiride, cediranib, camptothecin & Sulpiride, entecavir, colistin \\
\hline & & Table 5 continues \\
\hline PEPT1 & $\begin{array}{l}\text { Glycylsarcosine, cephalexin, cefadroxil, bestatin, } \\
\text { valacyclovir, enalapril, aminolevulinic acid, captopril, } \\
\text { dipeptides, tripeptides }\end{array}$ & Glycyl-proline \\
\hline PEPT2 & $\begin{array}{l}\text { Glycylsarcosine, cephalexin, cefadroxil, bestatin, } \\
\text { valacyclovir, enalapril, aminolevulinic acid, captopril, } \\
\text { dipeptides, tripeptides }\end{array}$ & Zofenopril, fosinopril \\
\hline
\end{tabular}

Table 6. Inhibitors and substrates affected by DDIs of the efflux transporters (Giacomini et al., 2010).

\section{Transporter}

MRP2

MRP4

\section{Substrate (affected)}

Glutathione and glucuronide conjugates, methotrexate, etoposide, mitoxantrone, valsartan, olmesartan, glucuronidated SN-38

Adefovir, tenofovir, cyclic AMP, dehydroepiandrosterone sulphate, methotrexate,

\section{Inhibitor}

Cyclosporine, delaviridine, efavirenz, emtricitabine

Celecoxib, diclofenac

Table 6 continues ... 
topotecan, furosemide, cyclic GMP, bile acids plus glutathione

P-gp Digoxin, loperamide, berberine, irinotecan, doxorubicin, vinblastine, paclitaxel, fexofenadine

Cyclosporine, quinidine, tariquidar, verapamil

Oestrone, $17 \beta$-oestradiol, fumitremorgin $\mathrm{C}$

Quinidine, cimetidine, procainamide

Cimetidine, quinidine, pramipexole

Table 7. Examples of P-gp inducers in brain, liver, intestine and kidney (Silva et al., 2015).

\begin{tabular}{ll} 
Organ & \multicolumn{1}{c}{ P-gp inducer } \\
\hline Brain & Abacavir; atazanavir; dexamethasone; dehydroxylated xanthones; insulin; ritonavir; morphine \\
Liver & $\begin{array}{l}\text { N-acetoxy-2acetylaminofluorene; 2-acetylaminofluorene; aflatoxinb1; amiodarone; } \\
\text { bromocriptine; dexamethasone; insulin; ivermectin; probenecid; rifampicin; TCDD }\end{array}$ \\
Intestine & $\begin{array}{l}\text { Amiodarone; benzo(a)pyrene; benzo(e)pyrene; bilirubin; budesonide; cadmium chloride; } \\
\text { caffeine; carbamazepine; corticosterone; cyclophosphamide; cyclosporine a; dexamethasone; } \\
\text { dehydroxylated xanthones; doxorubicin; phenobarbital; phenytoin; propranolol; quinidine; } \\
\text { rifampicin; verapamil }\end{array}$
\end{tabular}

Kidney Amiodarone; cyclosporine a; dexamethasone; dehydroxylated xanthones

\section{FINAL CONSIDERATIONS}

Kidney is the excretory organ of the human body, effecting the elimination of various metabolic waste products and xenobiotics (e.g., antiviral drugs and antibiotics). Tubular secretion is mostly performed in the proximal tubule in two phases (uptake of the compounds through the basolateral membrane and efflux of these same compounds through the apical membrane), these cells being more susceptible to damage. For this transport to occur, transporters, large proteins bound to basolateral and apical cell membranes, are present. Uptake transporters are frequently more efficient than efflux transporters resulting in a higher concentration of xenobiotics within the proximal tubular cell; i.e., compound accumulation occurs. The accumulated xenobiotics causes renal damage. In addition, drug-drug interactions may occur, in which the transporter may be inhibited, induced or activated by a particular substance, altering the excretion of other compounds, which can be problematic. Thus, all these phenomena demonstrate the importance of membrane transporters at the kidney level to the pharmacological and toxicological effects of drugs and other xenobiotics.

ACKNOWLEDGEMENTS: This work was supported by the Applied Molecular Biosciences Unit - UCIBIO which is financed by national funds from FCT (UIDB/04378/2020). Authors have no conflict of interest regarding the contents of this article. 


\section{ABBREVIATIONS}

\begin{tabular}{|c|c|}
\hline $\mathbf{A A}$ & Aristolochic acid \\
\hline $\mathbf{A B C}$ & ATP-binding cassette \\
\hline ADMET & $\begin{array}{l}\text { Absorption, distribution, } \\
\text { metabolism, excretion } \\
\text { and transport }\end{array}$ \\
\hline AKI & Acute kidney injury \\
\hline ATP & Adenosine triphosphate \\
\hline BCRP & $\begin{array}{l}\text { Breast cancer resistance } \\
\text { protein }\end{array}$ \\
\hline сAMP & $\begin{array}{l}\text { Cyclic adenosine } \\
\text { monophosphate }\end{array}$ \\
\hline cGMP & $\begin{array}{l}\text { Cyclic guanine } \\
\text { monophosphate }\end{array}$ \\
\hline
\end{tabular}

CNT Sodium-coupled concentrative nucleoside transporters

$\begin{array}{ll}\text { COX } & \text { Cyclooxygenase } \\ \text { CsA } & \text { Cyclosporine } \\ \text { Cys } & \text { L-cysteine } \\ \text { DDI } & \text { Drug-drug interaction } \\ \text { DNA } & \text { Deoxyribonucleic acid } \\ \text { ENT } & \begin{array}{l}\text { Equilibrative nucleoside } \\ \text { transporter }\end{array}\end{array}$

FDA Food and drug association

FRNS Frequently relapsing nephrotic syndrome

GSH Glutathione

HIV Human immunodeficiency virus

iAs Inorganic arsenium

MATE Multidrug and toxic compound extrusion

MDR Multidrug resistance protein

MeHg Methyl mercury

MRP Multi resistance protein

MRSA Methicillin-resistant

Staphylococcus aureus

MPP 1-methyl-4phenylpyridinium

MT Metallothionein

NAC N-acetylcysteine

NBD Nucleotide binding domain

NPT Sodium-phosphate transporter

NKT Novel kidney transporter
NSAID Nonsteroidal antiinflammatory drugs

OAT Organic anion

OATP Organic anion transporting polypeptides

OCT Organic cation transporter

OCTN Organic carnitine/cation transporters novel

OTA Ochratoxin A

PAH p-aminohippurate

PEPT Peptide transporter

PGT Prostaglandin transporter

P-gp P-Glycoprotein

PMAT Plasma membrane

monoamine transporter

$\begin{array}{ll}\text { PQ } & \text { Paraquat } \\ \text { PXE } & \text { Pseudoxanthoma }\end{array}$ elasticum

ROS Reactive oxygen species

RNA Ribonucleic acid

RNS Reactive nitrogen species

SAT Sulfate-anion antiporter

SOD Superoxide dismutase

SNP Single nucleotide polymorphisms

SLC Solute carrier

T3 Triiodothyronine

TCDD 2,3,7,8-

tetraclorodibenzodioxina

TEA Tetraethylammonium

TMD Trans membranes domains

TMH Trans membranes helices

URAT Urate transporter 


\section{REFERENCES}

1. George B, You D, Joy MS, Aleksunes LM. Xenobiotic transporters and kidney injury. Advanced Drug Delivery Reviews. 2017. DOI: 10.1016/j.addr.2017.01.005.

2. Radi ZA. Kidney Pathophysiology, Toxicology, and Drug-Induced Injury in Drug Development. Int $\mathbf{J}$ Toxicol. 2019. DOI: 10.1177/1091581819831701.

3. Robertson EE, Rankin GO. Human renal organic anion transporters: Characteristics and contributions to drug and drug metabolite excretion. Vol. 109, Pharmacology and Therapeutics. 2006. p. 399-412. DOI: 10.1016/j.pharmthera.2005.07.005.

4. Bunprajun T, Yuajit C, Noitem R, Chatsudthipong V. Exhaustive exercise decreases renal organic anion transporter 3 function. J Physiol Sci. 2019 Mar;69(2):245-51. DOI: 10.1007/s12576-018-0641-5.

5. Levey AS, Becker C, Inker LA. Glomerular Filtration Rate and Albuminuria for Detection and Staging of Acute and Chronic Kidney Disease in Adults: A Systematic Review. JAMA. 2015 Feb 24;313(8):837. DOI: 10.1001/jama.2015.0602.

6. Huo X, Liu K. Renal organic anion transporters in drugdrug interactions and diseases. Eur J Pharm Sci. 2018 Jan;112:8-19. DOI: 10.1016/j.ejps.2017.11.001.

7. Aleksunes LM, Augustine LM, Scheffer GL, Cherrington NJ, Manautou JE. Renal xenobiotic transporters are differentially expressed in mice following cisplatin treatment. Toxicology. 2008 Sep;250(2-3):82-8. DOI: 10.1016/j.tox.2008.06.009.

8. Brown CDA, Sayer R, Windass AS, Haslam IS, De Broe $\mathrm{ME}$, D'Haese PC, et al. Characterisation of human tubular cell monolayers as a model of proximal tubular xenobiotic handling. Toxicol Appl Pharmacol. 2008 Dec;233(3):428-38. DOI: 10.1016/j.taap.2008.09.018.

9. Shen H, Scialis RJ, Lehman-McKeeman L. Xenobiotic Transporters in the Kidney: Function and Role in Toxicity. Semin Nephrol. 2019 Mar;39(2):159-75. DOI: 10.1016/j.semnephrol.2018.12.010.

10. Döring B, Petzinger E. Phase 0 and phase III transport in various organs: Combined concept of phases in xenobiotic transport and metabolism. Drug Metab Rev. 2014 Aug;46(3):261-82. DOI: 10.3109/03602532.2014.882353.

11. Uchida Y, Toyohara T, Ohtsuki S, Moriyama Y, Abe T, Terasaki T. Quantitative Targeted Absolute Proteomics for 28 Transporters in Brush-Border and Basolateral Membrane Fractions of Rat Kidney. J Pharm Sci. 2016 Feb;105(2):1011-6. DOI: 10.1002/jps.24645.

12. Silva R, Vilas-Boas V, Carmo H, Dinis-Oliveira RJ, Carvalho F, de Lourdes Bastos M, et al. Modulation of P-glycoprotein efflux pump: induction and activation as a therapeutic strategy. Pharmacol Ther. 2015 May;149:1-123.

10.1016/j.pharmthera.2014.11.013.

13. Bush KT, Wu W, Lun C, Nigam SK. The drug transporter OAT3 (SLC22A8) and endogenous metabolite communication via the gut-liver-kidney axis. J Biol Chem. 2017 Sep 22;292(38):15789-803. DOI: $10.1074 /$ jbc.M117.796516.
14. Nigam SK, Wu W, Bush KT, Hoenig MP, Blantz RC, Bhatnagar V. Handling of Drugs, Metabolites, and Uremic Toxins by Kidney Proximal Tubule Drug Transporters. Clin J Am Soc Nephrol. 2015 Nov 6;10(11):2039-49. DOI: 10.2215/CJN.02440314.

15. DeGorter MK, Xia CQ, Yang JJ, Kim RB. Drug Transporters in Drug Efficacy and Toxicity. Annu Rev Pharmacol Toxicol. 2012 Feb 10;52(1):249-73. DOI: 10.1146/annurev-pharmtox-010611-134529.

16. Schlessinger A, Khuri N, Giacomini KM, Sali A. Molecular Modeling and Ligand Docking for Solute Carrier (SLC) Transporters. Curr Top Med Chem. 2013 May 1;13(7):843-56. DOI: 10.2174/1568026611313070007.

17. Liu HC, Jamshidi N, Chen Y, Eraly SA, Cho SY, Bhatnagar V, et al. An Organic Anion Transporter 1 (OAT1)-centered Metabolic Network. J Biol Chem. 2016 Sep 9;291(37):19474-86. DOI: https://doi.org/10.1038/ki.2010.337.

18. Ivanyuk A, Livio F, Biollaz J, Buclin T. Renal Drug Transporters and Drug Interactions. Clin Pharmacokinet. 2017 Aug;56(8):825-92. DOI: 10.1007/s40262-0170506-8.

19. Gameiro M, Silva R, Rocha-Pereira C, Carmo H, Carvalho F, Bastos M, et al. Cellular Models and In Vitro Assays for the Screening of modulators of P-gp, MRP1 and BCRP. Molecules. 2017 Apr 8;22(4):600. DOI: 10.3390/molecules22040600.

20. Klaassen CD, Lu H. Xenobiotic Transporters: Ascribing Function from Gene Knockout and Mutation Studies. Toxicol Sci. 2008 Feb;101(2):186-96. DOI: 10.1093/toxsci/kfm214.

21. Momper JD, Yang J, Gockenbach M, Vaida F, Nigam SK. Dynamics of Organic Anion Transporter-Mediated Tubular Secretion during Postnatal Human Kidney Development and Maturation. Clin J Am Soc Nephrol. 2019 Apr 5;14(4):540-8. DOI: 10.2215/CJN.10350818.

22. Nigam SK. The SLC22 Transporter Family: A Paradigm for the Impact of Drug Transporters on Metabolic Pathways, Signaling, and Disease. Annu Rev Pharmacol Toxicol. 2018 Jan 6;58(1):663-87. DOI: 10.1146/annurev-pharmtox-010617-052713.

23. Nigam SK. What do drug transporters really do? Nat Rev Drug Discov. 2015 Jan;14(1):29-44. DOI: 10.1038/nrd4461.

24. Vormann MK, Gijzen L, Hutter S, Boot L, Nicolas A, van den Heuvel A, et al. Nephrotoxicity and Kidney Transport Assessment on 3D Perfused Proximal Tubules. AAPS J. 2018 Sep;20(5):90. DOI: 10.1208/s12248-018-0248-z.

25. Hyndman D, Liu S, Miner JN. Urate Handling in the Human Body. Curr Rheumatol Rep. 2016 Jun;18(6):34. DOI: $10.1007 / \mathrm{s} 11926-016-0587-7$.

26. Maiuolo J, Oppedisano F, Gratteri S, Muscoli C, Mollace V. Regulation of uric acid metabolism and excretion. Int J Cardiol. 2016 Jun;213:8-14. DOI: 10.1016/j.ijcard.2015.08.109

27. Pan Y, Kong L-D. Urate transporter URAT1 inhibitors: a patent review (2012 - 2015). Expert Opin Ther Pat. 
2016 Oct 2;26(10):1129-38. DOI: 40. 10.1080/13543776.2016.1213243.

28. Tan PK, Ostertag TM, Miner JN. Mechanism of high affinity inhibition of the human urate transporter URAT1. Sci Rep. 2016 Dec;6(1):34995. DOI: 10.1038/srep34995.

29. Wagner DJ, Hu T, Wang J. Polyspecific organic cation transporters and their impact on drug intracellular levels and pharmacodynamics. Pharmacol Res. 2016 Sep;111:237-46. DOI: 10.1016/j.phrs.2016.06.002.

30. Cheung KWK, Hsueh C-H, Zhao P, Meyer TW, Zhang L, Huang S-M, et al. The Effect of Uremic Solutes on the Organic Cation Transporter 2. J Pharm Sci. 2017 Sep;106(9):2551-7. DOI: 10.1016/j.xphs.2017.04.076.

31. Yin J, Duan H, Shirasaka Y, Prasad B, Wang J. Atenolol Renal Secretion Is Mediated by Human Organic Cation Transporter 2 and Multidrug and Toxin Extrusion Proteins. Drug Metab Dispos. 2015 Dec;43(12):187281. DOI: $10.1124 / \mathrm{dmd} .115 .066175$.

32. Sato T, Mishima E, Mano N, Abe T, Yamaguchi H. Potential Drug Interactions Mediated by Renal Organic Anion Transporter OATP4C1. J Pharmacol Exp Ther. 2017 Aug;362(2):271-7. DOI: 10.1124/jpet.117.241703.

33. Robertson EE, Rankin GO. Human renal organic anion transporters: Characteristics and contributions to drug and drug metabolite excretion. Pharmacol Ther. 2006 Mar;109(3):399-412.

10.1016/j.pharmthera.2005.07.005.

34. Pochini L, Galluccio M, Scalise M, Console L, Indiveri C. OCTN: A Small Transporter Subfamily with Great Relevance to Human Pathophysiology, Drug Discovery, and Diagnostics. SLAS Discov Adv Life Sci RD. 2019 Feb;24(2):89-110. DOI: 10.1177/2472555218812821.

35. Gomez-Zepeda D, Taghi M, Smirnova M, Sergent P, Liu W-Q, Chhuon C, et al. LC-MS/MS-based quantification of efflux transporter proteins at the BBB. J Pharm Biomed Anal. 2019 Feb;164:496-508. DOI: 10.1016/j.jpba.2018.11.013.

36. Dean M. The Human ATP-Binding Cassette (ABC) Transporter Superfamily. Genome Res. 2001 Jul 1;11(7):1156-66. DOI: 10.1101/gr.GR-1649R.

37. Keppler D. Multidrug Resistance Proteins (MRPs, ABCCs): Importance for Pathophysiology and Drug Therapy. In: Fromm MF, Kim RB, editors. Drug Transporters [Internet]. Berlin, Heidelberg: Springer Berlin Heidelberg; 2011 [cited 2019 Nov 18]. p. 299323. Available from: http://link.springer.com/10.1007/978-3-642-14541-4_8

38. Hira D, Terada T. BCRP/ABCG2 and high-alert medications: Biochemical, pharmacokinetic, pharmacogenetic, and clinical implications. Biochem Pharmacol. 2018 Jan;147:201-10.

39. Cascorbi I. P-glycoprotein: Tissue Distribution, Substrates, and Functional Consequences of Genetic Variations. In: Fromm MF, Kim RB, editors. Drug Transporters [Internet]. Berlin, Heidelberg: Springer Berlin Heidelberg; 2011 [cited 2019 Nov 18]. p. 261-83. Available from: http://link.springer.com/10.1007/978-3642-14541-4_6
Konieczna A, Erdösová B, Lichnovská R, Jandl M, Čížková K, Ehrmann J. Differential expression of ABC transporters (MDR1, MRP1, BCRP) in developing human embryos. J Mol Histol. 2011 Dec;42(6):567-74. DOI: $10.1007 / \mathrm{s} 10735-011-9363-1$.

41. Huls M, Brown CDA, Windass AS, Sayer R, van den Heuvel JJMW, Heemskerk S, et al. The breast cancer resistance protein transporter $\mathrm{ABCG} 2$ is expressed in the human kidney proximal tubule apical membrane. Kidney Int. 2008 Jan;73(2):220-5. DOI: 10.1038/sj.ki.5002645.

42. Mao Q, Unadkat JD. Role of the Breast Cancer Resistance Protein (BCRP/ABCG2) in Drug Transport-an Update. AAPS J. 2015 Jan;17(1):65-82. DOI: $10.1208 / \mathrm{s} 12248-014-9668-6$.

43. Staud F, Cerveny L, Ahmadimoghaddam D, Ceckova M. Multidrug and toxin extrusion proteins (MATE/SLC47); role in pharmacokinetics. Int J Biochem Cell Biol. 2013 Sep;45(9):2007-11. DOI: 10.1016/j.biocel.2013.06.022. Nies AT, Damme K, Kruck S, Schaeffeler E, Schwab M. Structure and function of multidrug and toxin extrusion proteins (MATEs) and their relevance to drug therapy and personalized medicine. Arch Toxicol. 2016 Jul;90(7):1555-84. DOI: 10.1007/s00204-016-1728-5.

45. Motohashi H, Inui K. Multidrug and toxin extrusion family SLC47: Physiological, pharmacokinetic and toxicokinetic importance of MATE1 and MATE2-K. Mol Aspects Med. 2013 Apr;34(2-3):661-8. DOI: 10.1016/j.mam.2012.11.004.

46. Fisel P, Nies AT, Schaeffeler E, Schwab M. The importance of drug transporter characterization to precision medicine. Expert Opin Drug Metab Toxicol. 2017 Apr 3;13(4):361-5. DOI: 10.1080/17425255.2017.1290083.

47. Ranzani GN, Gregori S, Gregori M, Regazzi M, Govoni S. Interindividual variability of drug transporters: Impact on opioid treatment in chronic renal failure. Eur J Pain Suppl. $2009 \quad$ Nov;3(S2):21-8. DOI: 10.1016/j.eujps.2009.07.010.

48. Joseph S, Nicolson TJ, Hammons G, Word B, GreenKnox B, Lyn-Cook B. Expression of drug transporters in human kidney: impact of sex, age, and ethnicity. Biol Sex Differ. 2015 Dec;6(1):4. DOI: 10.1186/s13293-0150020-3.

49. Prasad B, Johnson K, Billington S, Lee C, Chung GW, Brown CDA, et al. Abundance of Drug Transporters in the Human Kidney Cortex as Quantified by Quantitative Targeted Proteomics. Drug Metab Dispos. 2016 Dec;44(12):1920-4. DOI: 10.1124/dmd.116.072066.

50. Carrero JJ, Hecking M, Chesnaye NC, Jager KJ. Sex and gender disparities in the epidemiology and outcomes of chronic kidney disease. Nat Rev Nephrol. 2018 Mar;14(3):151-64. DOI: 10.1038/nrneph.2017.181.

51. Lash LH. Environmental and Genetic Factors Influencing Kidney Toxicity. Semin Nephrol. 2019 Mar;39(2):132-40.

10.1016/j.semnephrol.2018.12.003.

52. Zhou Y, Yang Y, Wang P, Wei M, Ma Y, Wu X. Adefovir accumulation and nephrotoxicity in renal interstitium: Role of organic anion transporters of 
kidney. Life Sci. 2019 May;224:41-50. DOI: 10.1016/j.lfs.2019.03.042.

53. Fanos V, Cataldi L. Renal Transport of Antibiotics and Nephrotoxicity: a Review. J Chemother. 2001 Jan;13(5):461-72. DOI: 10.1179/joc.2001.13.5.461.

54. Tavafi M. Inhibition of gentamicin-induced renal tubular cell necrosis. J Nephropathol. 2012 Jul 1;1(2):83-6. DOI: 10.5812/nephropathol.7512.

55. Lopez-Novoa JM, Quiros Y, Vicente L, Morales AI, Lopez-Hernandez FJ. New insights into the mechanism of aminoglycoside nephrotoxicity: an integrative point of view. Kidney Int. 2011;79(1):33-45. DOI: https://doi.org/10.1038/ki.2010.337.

56. Gai Z, Visentin M, Hiller C, Krajnc E, Li T, Zhen J, et al. Organic Cation Transporter 2 Overexpression May Confer an Increased Risk of Gentamicin-Induced Nephrotoxicity. Antimicrob Agents Chemother. 2016 Sep;60(9):5573-80. DOI: 10.1128/AAC.00907-16.

57. Ramalakshmi S, Bastacky S, Johnson JP. Levofloxacininduced granulomatous interstitial nephritis. Am J Kidney Dis. 2003 Feb;41(2):e7.1-e7.5. DOI: 10.1053/ajkd.2003.50064.

58. Famularo G, Simone CD. Nephrotoxicity and Purpura Associated with Levofloxacin. Ann Pharmacother. 2002;36:1380-1382.

https://doi.org/10.1345/aph.1A474.

59. Elyasi S, Khalili H, Dashti-Khavidaki S, Mohammadpour A. Vancomycin-induced nephrotoxicity: mechanism, incidence, risk factors and special populations. A literature review. Eur J Clin Pharmacol. 2012 Sep;68(9):1243-55. DOI: 10.1007/s00228-012-1259-9.

60. Izzedine H, Launay-Vacher V, Deray G. Antiviral DrugInduced Nephrotoxicity. Am J Kidney Dis. 2005 May;45(5):804-17. DOI: 10.1053/j.ajkd.2005.02.010.

61. Tanji N, Tanji K, Kambham N, Markowitz GS, Bell A, D'Agati VD. Adefovir nephrotoxicity: Possible role of mitochondrial DNA depletion. Hum Pathol. 2001 Jul;32(7):734-40. DOI: 10.1053/hupa.2001.25586.

62. Ortiz A, Justo P, Sanz A, Melero R, Caramelo C, Guerrero MF, et al. Tubular cell apoptosis and cidofovirinduced acute renal failure. Antivir Ther. 2005;6.

63. Perazella MA. Tenofovir-induced kidney disease: an acquired renal tubular mitochondriopathy. Kidney Int. 2010 Dec;78(11):1060-3. DOI: 10.1038/ki.2010.344.

64. Rifkin BS, Perazella MA. Tenofovir-associated nephrotoxicity: Fanconi syndrome and renal failure. Am J Med. 2004 Aug;117(4):282-4. DOI: 10.1016/j.amjmed.2004.03.025.

65. Fernandez-Fernandez B, Montoya-Ferrer A, Sanz AB, Sanchez-Niño MD, Izquierdo MC, Poveda J, et al. Tenofovir Nephrotoxicity: 2011 Update. AIDS Res Treat. 2011;2011:1-11. DOI: 10.1155/2011/354908.

66. Fleischer R, Johnson M. Acyclovir Nephrotoxicity: A Case Report Highlighting the Importance of Prevention, Detection, and Treatment of Acyclovir-Induced Nephropathy. Case Rep Med. 2010;2010:1-3. DOI: 10.1155/2010/602783.

67. Harrach S, Ciarimboli G. Role of transporters in the distribution of platinum-based drugs. Front Pharmacol
[Internet]. 2015 Apr 24 [cited 2019 Nov 15];6. Available from:

http://journal.frontiersin.org/article/10.3389/fphar.2015. 00085/abstract

68. Manohar S, Leung N. Cisplatin nephrotoxicity: a review of the literature. J Nephrol. 2017 Apr 5;1-11. DOI: DOI: 10.1007/s40620-017-0392-z.

69. Arany I, Safirstein RL. Cisplatin nephrotoxicity. Semin Nephrol. 2003 Sep;23(5):460-4. DOI: 10.1016/S02709295(03)00089-5.

70. Damiano S, Ciarcia R, Montagnaro S, Pagnini U, Garofano T, Capasso G, et al. Prevention of Nephrotoxicity Induced by Cyclosporine-A: Role of Antioxidants: ANTIOXIDANTS IN CsA NEPHROTOXITY. J Cell Biochem. 2015 Mar;116(3):364-9. DOI: 10.1002/jcb.25022.

71. Hamasaki Y, Komaki F, Ishikura K, Hamada R, Sakai T, Hataya $\mathrm{H}$, et al. Nephrotoxicity in children with frequently relapsing nephrotic syndrome receiving longterm cyclosporine treatment. Pediatr Nephrol. 2017 Aug;32(8):1383-90. DOI: 10.1007/s00467-017-3641-4.

72. Kotowski MJ, Bogacz A, Bartkowiak-Wieczorek J, Tejchman K, Dziewanowski K, Ostrowski M, et al. Effect of Multidrug-Resistant 1 (MDR1) and CYP3A4*1B Polymorphisms on Cyclosporine-Based Immunosuppressive Therapy in Renal Transplant Patients. Ann Transplant. 2019 Feb 25;24:108-14. DOI: 10.12659/AOT.914683.

73. Cheng H, Harris R. Renal Effects of Non-Steroidal AntiInflammatory Drugs and Selective Cyclooxygenase-2 Inhibitors. Curr Pharm Des. 2005 May 1;11(14):1795804. DOI: $10.2174 / 1381612053764922$.

74. Markowitz GS, Bomback AS, Perazella MA. DrugInduced Glomerular Disease: Direct Cellular Injury. Clin J Am Soc Nephrol. 2015 Jul 7;10(7):1291-9. DOI: 10.2215/CJN.00860115.

75. Raghavan R, Shawar S. Mechanisms of Drug-Induced Interstitial Nephritis. Adv Chronic Kidney Dis. 2017 Mar;24(2):64-71. DOI: 10.1053/j.ackd.2016.11.004.

76. Lafrance J-P, Miller DR. Selective and non-selective non-steroidal anti-inflammatory drugs and the risk of acute kidney injury. Pharmacoepidemiol Drug Saf. 2009 Oct;18(10):923-31. DOI: 10.1002/pds.1798.

77. Huerta C, Varas-Lorenzo C, Castellsague J, Garcia Rodriguez LA. Non-steroidal anti-inflammatory drugs and risk of first hospital admission for heart failure in the general population. Heart. 2006 Nov 1;92(11):1610-5. DOI: $10.1136 /$ hrt.2005.082388.

78. Nolin TD, Himmelfarb J. Mechanisms of Drug-Induced Nephrotoxicity. In: Uetrecht J, editor. Adverse Drug Reactions [Internet]. Berlin, Heidelberg: Springer Berlin Heidelberg; 2010 [cited 2019 Nov 18]. p. 111-30. Available from: http://link.springer.com/10.1007/978-3642-00663-0_5

79. Ingrasciotta $\bar{Y}$, Sultana J, Giorgianni F, Fontana A, Santangelo A, Tari DU, et al. Association of Individual Non-Steroidal Anti-Inflammatory Drugs and Chronic Kidney Disease: A Population-Based Case Control Study. Seguro AC, editor. PLOS ONE. 2015 Apr 16;10(4):1-14. DOI: 10.1371/journal.pone.0122899. 
80. Ulinski T, Guigonis V, Dunan O, Bensman A. Acute renal failure after treatment with non-steroidal antiinflammatory drugs. Eur J Pediatr. 2004 Mar 1;163(3):148-50. DOI: 10.1007/s00431-003-1392-7.

81. House AA, Oliveira SS, Ronco C. Anti-Inflammatory Drugs and the Kidney. Int J Artif Organs. 2007 Dec;30(12):1042-6.

DOI: 94 $10.1177 / 039139880703001203$.

82. Song C, Fu B, Zhang J, Zhao J, Yuan M, Peng W, et al. Sodium fluoride induces nephrotoxicity via oxidative stress-regulated mitochondrial SIRT3 signaling pathway. Sci Rep. 2017 Dec;7(1):672. DOI: 10.1038/s41598-017-00796-3.

83. Cárdenas-González M, Jacobo Estrada T, RodríguezMuñoz R, Barrera-Chimal J, Bobadilla NA, Barbier OC, et al. Sub-chronic exposure to fluoride impacts the response to a subsequent nephrotoxic treatment with gentamicin: Fluoride exposure impacts the response to treatment with gentamicin. J Appl Toxicol. 2016 Feb;36(2):309-19. DOI: 10.1002/jat.3186.

84. Quadri J, Sarwar S, Sinha A, Kalaivani M, Dinda A, Bagga A, et al. Fluoride-associated ultrastructural changes and apoptosis in human renal tubule: a pilot study. Hum Exp Toxicol. 2018 Nov;37(11):1199-206. DOI: 10.1177/0960327118755257.

85. Barnett LMA, Cummings BS. Nephrotoxicity and Renal Pathophysiology: A Contemporary Perspective. Toxicol Sci. 2018 Aug 1;164(2):379-90. DOI: 10.1093/toxsci/kfy159.

86. Robles-Osorio ML, Sabath-Silva E, Sabath E. Arsenicmediated nephrotoxicity. Ren Fail. 2015 Apr 21;37(4):542-7.

10.3109/0886022X.2015.1013419.

87. Orr S, Bridges C. Chronic Kidney Disease and Exposure to Nephrotoxic Metals. Int J Mol Sci. 2017 May 12;18(5):1039. DOI: 10.3390/ijms18051039.

88. Yang H, Shu Y. Cadmium Transporters in the Kidney and Cadmium-Induced Nephrotoxicity. Int J Mol Sci. 2015 Jan 9;16(1):1484-94. DOI: 10.3390/ijms16011484.

89. Genchi G, Sinicropi M, Carocci A, Lauria G, Catalano A. Mercury Exposure and Heart Diseases. Int J Environ Res Public Health. 2017 Jan 12;14(1):74. DOI: 10.3390/ijerph14010074.

90. Costa JG, Saraiva N, Guerreiro PS, Louro H, Silva MJ, Miranda JP, et al. Ochratoxin A-induced cytotoxicity, genotoxicity and reactive oxygen species in kidney cells: An integrative approach of complementary endpoints. Food Chem Toxicol. 2016 Jan;87:65-76. DOI: 10.1016/j.fct.2015.11.018.

91. Malir F, Ostry V, Pfohl-Leszkowicz A, Novotna E. Ochratoxin A: Developmental and Reproductive Toxicity-An Overview: REPROTOXICITY OF OCHRATOXIN. Birth Defects Res B Dev Reprod Toxicol. 2013 Dec;98(6):493-502. DOI: 10.1002/bdrb.21091.

92. Anzai N, Jutabha P, Endou H. Molecular Mechanism of Ochratoxin A Transport in the Kidney. Toxins. 2010 Jun 9;2(6):1381-98. DOI: 10.3390/toxins2061381.
93. Dinis-Oliveira RJ, Duarte JA, Remião F, SánchezNavarro A, Bastos ML, Carvalho F. Single high dose dexamethasone treatment decreases the pathological score and increases the survival rate of paraquatintoxicated rats. Toxicology. 2006 Oct;227(1-2):73-85. DOI: 10.1016/j.tox.2006.07.025.

94. Chen Y, Zhang S, Sorani M, Giacomini KM. Transport of Paraquat by Human Organic Cation Transporters and Multidrug and Toxic Compound Extrusion Family. J Pharmacol Exp Ther. 2007 Aug;322(2):695-700. DOI: 10.1124/jpet.107.123554.

95. Silva R, Sousa E, Carmo H, Palmeira A, Barbosa DJ, Gameiro $\mathrm{M}$, et al. Induction and activation of $\mathrm{P}$ glycoprotein by dihydroxylated xanthones protect against the cytotoxicity of the P-glycoprotein substrate paraquat. Arch Toxicol. 2014 Apr;88(4):937-51. DOI: 10.1007/s00204-014-1193-y.

96. Tomita M, Okuyama T, Katsuyama H, Ishikawa T. Paraquat-induced gene expression in rat kidney. Arch Toxicol. 2006 Oct;80(10):687-93. DOI: 10.1007/s00204-006-0092-2.

97. Wunnapuk K, Liu X, Peake P, Gobe G, Endre Z, Grice JE, et al. Renal biomarkers predict nephrotoxicity after paraquat. Toxicol Lett. 2013 Oct;222(3):280-8. DOI: 10.1016/j.toxlet.2013.08.003.

98. Giacomini, KM, Huang, SM, Tweedie, DJ, Benet, LZ, Brouwer, KL, Chu, X, et al. Membrane transporters in drug development. Nat Rev Drug Discov. 2010 Mar;9(3):215-36. DOI: 10.1038/nrd3028.

99. König J, Müller F, Fromm MF. Transporters and DrugDrug Interactions: Important Determinants of Drug Disposition and Effects. Michel MC, editor. Pharmacol Rev. $2013 \quad$ Jul;65(3):944-66. DOI: 10.1124/pr.113.007518.

100. Caetano-Pinto P, Jansen J, Assaraf YG, Masereeuw R. The importance of breast cancer resistance protein to the kidneys excretory function and chemotherapeutic resistance. Drug Resist Updat. 2017 Jan;30:15-27. DOI: 10.1016/j.drup.2017.01.002.

101. Silva R, Palmeira A, Carmo H, Barbosa DJ, Gameiro M, Gomes A, et al. P-glycoprotein induction in Caco-2 cells by newly synthetized thioxanthones prevents paraquat cytotoxicity. Arch Toxicol. 2015 Oct;89(10):1783-800. DOI: 10.1007/s00204-014-1333-4.

102. Lopes A, Martins E, Silva R, Pinto M, Remião F, Sousa $\mathrm{E}$, et al. Chiral Thioxanthones as Modulators of Pglycoprotein: Synthesis and Enantioselectivity Studies. Molecules. 2018 Mar 10;23(3):626. DOI: 10.3390/molecules23030626.

103. del Moral RG, Olmo A, Aguilar M, O’Valle F. P Glycoprotein: A New Mechanism to Control DrugInduced Nephrotoxicity. Nephron Exp Nephrol. 1998 Mar 20;6(2):89-97. DOI: 10.1159/000020510. 